\title{
Gift Exchange in the Lab - It is not (only) how much you give ...
}

\author{
Florian Englmaier \\ Steve Leider
}

\section{CESIFO WORKING PAPER NO. 2944}

CATEGORY 4: LABOUR MARKETS

FEBRUARY 2010

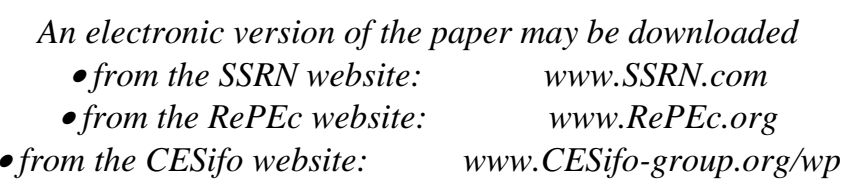




\title{
Gift Exchange in the Lab - It is not (only) how much you give ...
}

\begin{abstract}
An important aspect in determining the effectiveness of gift exchange relations in labor markets is the ability of the worker to "repay the gift" to the employer. To test this hypothesis, we conduct a real effort laboratory experiment where we vary the wage and the effect of the worker's effort on the manager's payoff. Furthermore we collect additional information that allows us to control for the workers' ability and whether they can be classified as reciprocal or not. From our agency model of reciprocal motivation we derive non-trivial predictions about which is the marginal worker (in terms of ability) affected by our experimental variation and how different types of individuals, selfish and reciprocal, will react to it. Our model does substantially better than other theories in organizing the data.
\end{abstract}

JEL-Code: C91, J33, M52.

Keywords: reciprocity, fairness, real effort experiment, personality tests.

\author{
Florian Englmaier \\ Department of Economics \\ University of Munich \\ Ludwigstrasse 28 III VG \\ 80539 Munich \\ Germany \\ englmaier@Imu.de
}

\author{
Steve Leider \\ University of Michigan \\ Ross School of Business \\ 701 Tappan Street R4486 \\ Ann Arbor MI 48109 \\ USA \\ leider@bus.umich.edu
}

February 1, 2010

We thank Greg Baron, Al Roth, Carmit Segal, and Christina Strassmair for very helpful discussions and the participants of the Tinbergen Institute conference 'Human Relations, Reciprocity, and Incentives in the Workplace' 2008 in Rotterdam, the ESEM 2009 in Barcelona, and the GEABA Conference 2009 in Vallendar for their comments. Florian Englmaier thanks the Harvard Business School for its hospitality and the German Science Foundation (DFG) for financial support via grant EN 784/2-1 and SFB/TR-15. Steve Leider thanks the National Science Foundation and the Sperry Fund for financial support. 


\section{Introduction}

The common use of compensation schemes with weak monetary incentives (and the ability of such schemes to induce employee effort) has long been a puzzle in economics. Starting with Akerlof (1982) a literature has developed that considers alternative sources of incentives in the workplace. Akerlof models the labor relation as a gift exchange where workers respond to generous treatment by the firm (i.e. generous wage levels) by exerting above minimal effort. Many laboratory experiments have corroborated the power of gift exchange as a source, see Fehr and Falk (2008) for a survey. However, it is important to understand what determines how well motivating workers via gift exchange works and how it can be made more effective. ${ }^{1}$ We argue that a key determinant of the efficacy of using reciprocal motivation to provide incentives is the ability of a worker to repay a gift, i.e. the magnitude of the benefit accruing to the manager from high effort by the worker. If effort by the worker provides little to no benefit to the manager, then even a highly reciprocal worker given a very generous wage may not provide much effort.

We test this hypothesis in the lab using a real effort task where we manipulate the extent to which the manager benefits from worker effort. In our experiment subjects in the role of the "manager" could hire subjects in the role of the "worker" to perform a coding task, where workers have to match as many words to a specific code as possible in a pre-specified time period of 25 minutes, for a fixed wage payment of $\$ 10$. The manager's pay depended on the number of correct answers by the workers (guessing was discouraged with a penalty). We exogenously varied how much one correct answer was worth to the manager, and we gave the managers the option to offer the workers a higher flat wage $(\$ 20)$ than the one publicly announced at the beginning of the experiment. Thus we vary both the size of the initial wage gift and the effect of worker effort on the manager's payoff. In the next part of the experiment, all agents had to complete the coding task for five minutes under a piece rate for correct answers (again, guessing was discouraged with a penalty). We use the score from this test as a measure of individual ability. In addition, the subjects played a standard trust game, which we use to classify them as reciprocal or not, and fill out a "Big 5" personality test which we use to classify their personality type. We use this additional information to more precisely estimate the impact of a wage gift.

\footnotetext{
${ }^{1}$ An example for work in this vein is Irlenbusch and Sliwka (2005) who investigate the impact of transparency on the effectiveness of gift exchange.
} 
It is intuitive to argue that there should be a complementarity between initial gift and the ability to give back. Considering a simple agency model with reciprocal motivation, we can derive nuanced predictions on the sets of agents affected by the treatment variations which other competing theories cannot get. To capture reciprocity, a concept formally described by Rabin (1993) for normal form games and by Dufwenberg and Kirchsteiger (2004) and Falk and Fischbacher (2006) for sequential games, we assume that the worker's utility increases in the manager's revenue whenever the manager provides the worker with a rent in excess of his outside option. Thus when the manager is generous to the worker by giving him something valuable (additional compensation), the worker desires to provide in turn something of value to the manager (high effort). The worker's reciprocal attitude can now be used by the manager to align the worker's preferences with those of the manager, thus generating intrinsic motivation. A worker's decision whether to reciprocate will depend on whether his extra effort costs are outweighed by his extra utility from reciprocity. The latter will depend on four components: The worker's concern for reciprocity, the size of the initial gift (i.e. the generosity of the wage offer), the effect of the extra effort on the manager's revenue, and the worker's ability (i.e. the inverse of his effort costs). We derive two main comparative statics on the nature of the optimal contract. A worker has a greater gift exchange-based incentive to work hard if, ceteris paribus, he is more intrinsically reciprocal or when the effect of his effort on the manager's payoff is greater. Furthermore, the wage and the benefit to the manager are complements in the workers utility function and hence, while varying only one of these instruments will suffice to induce only the (relatively) high ability workers to exert high effort, changing both is necessary to also entice the (relatively) low ability workers to work harder.

In particular, we make the following predictions about which workers, in terms of ability, will be influenced by a change in wage. 1) When the effect of output on the manager's payoff is small, the high ability workers will be induced to exert effort by a high wage relative to a low wage. 2) When the effect of output on the manager's payoff is larger, the low ability workers will be induced to exert effort by a high wage, relative to a low wage. 3) Furthermore we can show that the response to these variations is stronger for more reciprocal individuals. These detailed predictions allow us to make a more specific test of the effectiveness of gift-exchange.

The results of the experiment confirm our predictions from above. In the treatment where the manager has a small benefit from effort, we observe a significant positive response to 
high wages among high ability workers, but not overall. In the high payoff condition we find a significant overall response to the high wage (between $2 \%$ and $11 \%$ ), particularly among the low ability workers (since in the high payoff treatment high ability workers exerted extensive effort already without the high wage). We find that this positive response is stronger among highly reciprocal subjects, where it is not important whether reciprocal inclination is measured directly via a trust game or indirectly via a personality test. Hence our findings might have a wider applicability as personality tests are a prominent element in firms' hiring procedures. Using them allows firms to screen for reciprocal workers and make use of the workers' reciprocal motivation, in the process tailoring their incentive and organizational structure to get the most out of them.

An extensive body of evidence has developed, demonstrating reciprocal behavior and gift exchange in laboratory experiments. Fehr and Falk (2008) summarize the findings from previous studies and highlight several key results: 1) Average wages in the experiments are above the minimal wages and leave workers with rents. 2) There is a positive wage-effort relationship. 3) These results are robust to various institutions, to competition, and to high stakes. ${ }^{2}$ Among the many variations of gift exchange games that have been run, two recent laboratory experiments seem particularly related to our study. Hennig-Schmidt et al (2008) present a real-effort laboratory experiment and show that a positive wage-effort relation as implied by gift exchange only prevails if information on the employer's surplus is provided to the experimental workers. This indicates, as predicted by our model, that the employer's surplus is an important determinant of the effectiveness of gift exchange relations. Note, however, that Hennig-Schmidt et al (2008) do neither vary the surplus accruing to the manager nor collect the additional information necessary to test our hypotheses. Maximiano et al (2007) show that the effectiveness of gift exchange, i.e. the positive wage-effort relation, is only marginally weakened in a treatment where each employer has four workers (as compared to the classic bilateral gift exchange game). Because in their design each of the workers has the same impact on the employer's payoff, our model of reciprocity would predict that increasing the firm size should have no effect on the effectiveness of gift exchange. Hence our predictions are consistent with their results. ${ }^{3}$

\footnotetext{
${ }^{2}$ For further reference see also Fehr and Gaechter (2000) or Fehr and Schmidt (2003) and the references therein.

${ }^{3}$ There have also recently been a number of field experiments with mixed results on the effect of gift exchange in natural settings. Falk (2007) reports strong evidence for gift exchange in the context of charitable donations. On the other hand, Gneezy and List (2006) hire students for a day job and document
} 
The rest of the paper is structured as follows. Section 2 describes the details of the experiment, Section 3 derives the theoretical predictions, Section 4 sets out and analyzes the experimental results and Section 5 concludes. The Appendix contains some proofs, additional tables and figures and the experimental instructions.

\section{Experimental Design}

The experiment took place in the CLER lab at Harvard Business School. We ran 20 sessions in July 2007. In total we had 229 subjects from the CLER lab subject database participating. They were told that they are participating in a study on decision making behavior in markets. All subjects received a show-up fee of $\$ 10$. The workers were exogenously assigned to be either workers (192) or managers (37). Detailed instructions for the lab experiment can be found in Appendix C. ${ }^{4}$

In our experiment, subjects in the manager role could hire a worker to perform a "coding task" where workers have to match as many words to a specific code as possible in a prespecified time period of 25 minutes. We announced publicly that managers could choose to hire workers at a fixed wage payment of $\$ 10$. If the manager chose not to hire a worker, they both got $\$ 0$. No manager chose not to hire a worker. Managers could also choose to surprise the worker with a fixed wage payment of $\$ 20$, i.e. substantially higher than the $\$ 10$ publicly announced at the beginning of the experiment. ${ }^{5}$ By doing so we observed two values for the size of the wage "gift" the workers received from the manager, i.e. we endogenously create two different wage conditions for the workers. If the manager decided not to offer the higher wage, the worker never learned about this option. The manager's pay depended on the number of correct answers solved by the workers (guessing was discouraged with a penalty). To balance the number of observations between high and low wage offers, we matched multiple workers to some managers.

We exogenously created two different payoff conditions for the managers:

Low Payoff Condition The manager receives $\$ 40$, plus a premium of $\$ 0.04$ for every correct answer of the worker in the coding task, minus a penalty of $\$ 0.01$ for every incorrect

that there is only a short lived effect of a surprise rise of their hourly pay on the students' effort.

${ }^{4}$ On average the experiment lasted 60 minutes. Mean subject earnings were $\$ 29.43$.

${ }^{5}$ Of the 37 managers, 3 chose to pay the higher wage of $\$ 20$. 
answer, minus the wage payment to the worker. Eg., if the manager hires a worker for a $\$ 10$ wage and the worker has 200 correct and 3 incorrect answers the manager's payoff is given by $\$ 40+200 * \$ 0.04-3 * \$ 0.01-\$ 10=\$ 37.97$.

High Payoff Condition The manager receives $\$ 10$, plus a premium of $\$ 0.20$ for every correct answer of the worker in the coding task, minus a penalty of $\$ 0.05$ for every incorrect answer, minus the wage payment to the worker. Eg., if the manager hires a worker for a $\$ 10$ wage and the worker has 200 correct and 3 incorrect answers the manager's payoff is given by $\$ 10+200 * \$ 0.20-3 * \$ 0.05-\$ 10=\$ 39.85$.

Based on previous tests on the coding task, we picked the fixed and variable components of the manager's pay such that the average payoff of a manager should be roughly the same across the two conditions in order to minimize the role for unconditional distributional preferences. ${ }^{6}$ Hence we can perform a between subjects analysis as subjects were randomly allocated into one of four treatment conditions (\$10 wage/low payoff, \$20 wage/low payoff, \$10 wage/high payoff, \$20 wage/high payoff).

In order to control for differing ability we had all subjects do the coding task for 5 minutes after the main treatment was completed with a piece rate of $\$ 0.30$ per correct answer and a penalty of $\$ 0.08$ per incorrect answer in order to discourage guessing. We use the individual performance in this piece rate treatment to infer the workers' differing abilities (or costs of effort respectively). ${ }^{7}$

In order to be able to test our prediction with respect to reciprocity we had workers play a trust game which we called the "sending task". In the sending task, both the Sender $[S]$ and the Receiver $[R]$ were given $\$ 10$. $S$ can choose to send between $\$ 0$ and $\$ 10$ to $R$. Any amount sent was tripled and $S$ kept any money that was not sent to $R$. $R$ can then send back any amount up to the total amount received. We used the strategy method and the subjects were asked for their decision profile in both roles. We randomly picked one of the roles and randomly matched it with one of the other participants' decisions to determine the payoff from this task. In order to relate our findings to real world hiring practices (which very rarely involve eliciting trust game responses from applicants) we had workers

\footnotetext{
${ }^{6}$ In fact the overall average number of correct answers was roughly 197, i.e. very close to the 200 we assumed for this calibration.

${ }^{7}$ On average the subjects answered 47.7 questions correctly with a standard deviation of 12.1, a minimum of 7 , and a maximum of 87 . We do not find any significant influence of prior treatment assignment on the performance in the test.
} 
take a "Big 5" personality test, which is commonly used by firms in their hiring procedures (see Autor and Scarborough, 2008).

The final payment of the subjects was determined by a dice and was either their payoff from the worker/manager coding task, the piece rate coding task or the sending task.

\section{Theoretical Predictions}

\subsection{A simple Model of reciprocal Motivation}

To derive our hypotheses we consider a simple model that captures the intuition of the experiment. $^{8}$ Assume there is a risk neutral manager who wants to maximize expected profits and a risk averse worker who cares about reciprocity. Assume that there are $n$ states of the world that are characterized by payoffs $q_{i}$ with $i=1, \ldots, n$ respectively. The worker can take one of two actions (effort levels) $a_{1}$ and $a_{2}$ with $a_{1}<a_{2}$ and corresponding costs from effort $c(\cdot)$ with $c\left(a_{2}\right)-c\left(a_{1}\right)=\Delta c>0$. The two actions imply respective probabilities of the states $\pi_{i}\left(a_{1}\right)$ and $\pi_{i}\left(a_{2}\right)$ where for the respective expected return of the manager $E R\left(a_{2}\right)=\sum \pi_{i}\left(a_{2}\right) q_{i}>\sum \pi_{i}\left(a_{1}\right) q_{i}=E R\left(a_{1}\right)$ holds. In order to capture our experimental variation we introduce the scalar $M$ which reflects the monetary value of output $q_{i}$ to the manager, i.e. $M \cdot E R\left(a_{i}\right)$ is the expected monetary gross return for the manager from action $a_{i}$ and $M \cdot \Delta E R=M \cdot E R\left(a_{2}\right)-M \cdot E R\left(a_{1}\right)$ is the gross benefit for the manager if the worker chooses $a_{2}$ instead of $a_{1}$.

A contract $(w, \hat{a})$ is a fixed wage payment $w$, as well as an expected action $\hat{a}$. In a real world context we could think of $\hat{a}$ as an informal job description or a code of conduct. In the lab we will interpret $\hat{a}$ as a commonly understood norm. Given our focus here on changes in behavior these details are not key to our results. While $\hat{a}$ is not binding, in the model it serves to fix the worker's beliefs about the manager's intended generosity (since the expected utility of a contract depends on the worker's action).

The worker's inherent concern for reciprocity is measured by $\eta \in[0,+\infty)$. We allow for potentially differing costs of effort (i.e. differing abilities), captured by a scalar $\gamma>0$. The

\footnotetext{
${ }^{8}$ We consider a simplified version of the model in Englmaier and Leider (2008) who solve the full moral hazard problem and derive the structure of optimal contracts in a standard principal agent problem with reciprocal agents.
} 
worker's utility function under the contract $(\tilde{w}, \hat{a})$, given that he takes action $a^{\prime}$, is given by

$$
U\left(a^{\prime}, \hat{a}\right)=u(\tilde{w})-\gamma c\left(a^{\prime}\right)+\eta(u(\tilde{w})-\gamma c(\hat{a})-\bar{u}) M \cdot E R\left(a^{\prime}\right)
$$

where $\bar{u}$ is the worker's outside option. The utility function consists of three parts:

i) utility from the monetary wage payment $u(\tilde{w})$, ii $)$ reciprocal utility $\eta(u(\tilde{w})-\gamma c(\hat{a})-\bar{u}) M$. $E R\left(a^{\prime}\right)$, and iii) effort costs $\gamma c\left(a^{\prime}\right)$.

Hence a "generous" contract is one that provides a rent to the worker, i.e. an expected monetary utility in excess of the worker's outside option. A more generous contract will induce the worker to feel more reciprocal, which here means that he will derive greater marginal and absolute utility from the manager's revenue.

Now consider the decision of a worker whether to work hard, i.e. choose $a_{2}$, or not. To make the problem non-trivial, assume the manager wants to implement $a_{2}$. A worker will prefer to choose $a_{2}$ over $a_{1}$ if and only if

$$
\begin{aligned}
U\left(a_{2}, a_{2}\right) & \geq U\left(a_{1}, a_{2}\right) \\
\eta\left(u(\tilde{w})-\gamma c\left(a_{2}\right)-\bar{u}\right) M \cdot \Delta E R & \geq \gamma \Delta c \\
\frac{\eta(u(\tilde{w})-\bar{u}) M \cdot \Delta E R}{\eta c\left(a_{2}\right) M \cdot \Delta E R+\Delta c} & \geq \gamma^{*}
\end{aligned}
$$

This condition immediately tells us, that for a given wage $\tilde{w}$ and a given monetary value $M$ only workers with effort costs below a critical threshold $\gamma^{*}$ will choose to work hard, i.e. those with relatively high ability. This threshold can be relaxed (i.e. more people be induced to choose $a_{2}$ ) if $M$ (the monetary value to the manager) is increased or when a higher wage is paid (i.e. increasing $u(\tilde{w})$ ). An increase in $\eta$, the worker's reciprocal inclination has the same effect as an increase in $M$. The following Lemma 1 summarizes these results.

Lemma 1 [Reciprocity] The critical value for working hard, $\gamma^{*}$, is strictly positive and defined by

$$
\frac{\eta(u(\tilde{w})-\bar{u}) M \cdot \Delta E R}{\eta c\left(a_{2}\right) M \cdot \Delta E R+\Delta c}=\gamma^{*} .
$$

$\gamma^{*}$ increases in $M$ and $\tilde{w}$ and $M$ and $\tilde{w}$ are complementary:

$$
\frac{\partial \gamma^{*}}{\partial M}>0, \quad \frac{\partial \gamma^{*}}{\partial \tilde{w}}>0, \quad \frac{\partial^{2} \gamma^{*}}{\partial M \partial \tilde{w}}>0
$$


Figure 1: Behavioral Predictions - Marginally Affected Agent Low Value to Principal

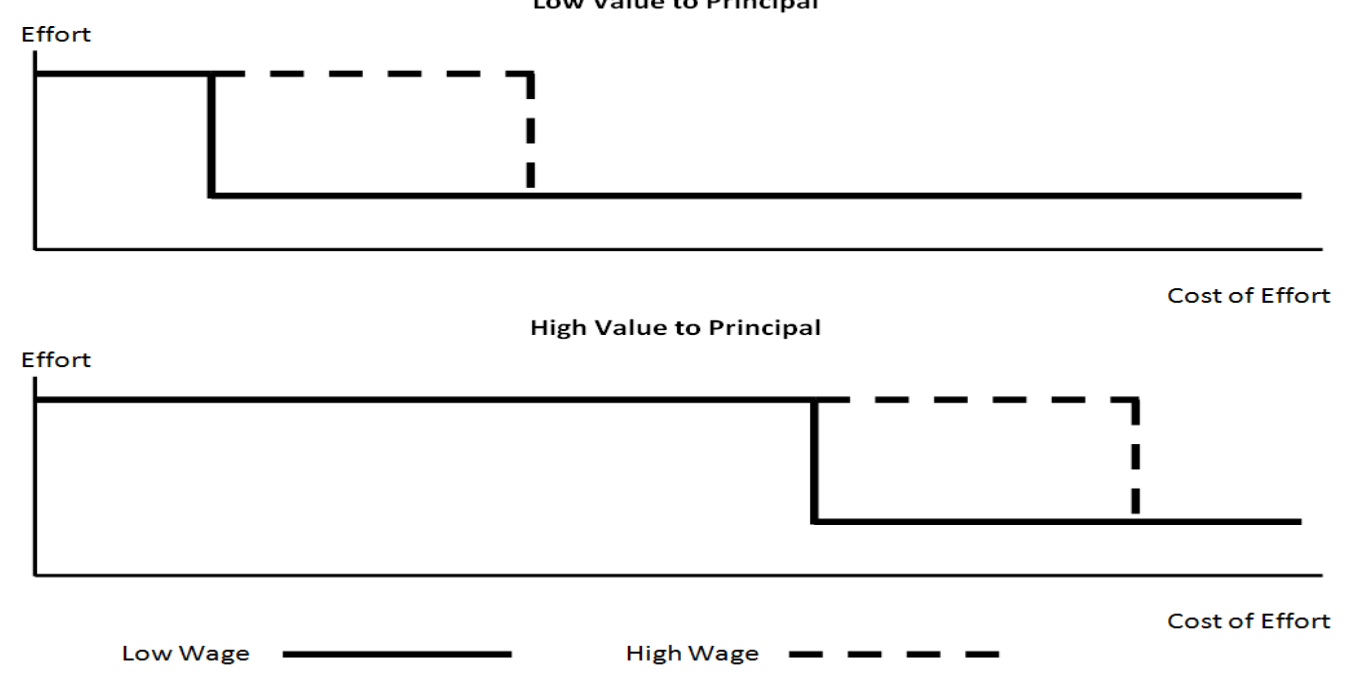

Furthermore $\gamma^{*}$ increases in $\eta$

$$
\frac{\partial \gamma^{*}}{\partial \eta}>0
$$

It is important to note, that this implies that for a high $M$ workers with relatively lower ability will be affected by a wage increase. Intuitively speaking, increasing either $M$ or $\tilde{w}$ alone does not suffice to induce the low ability workers to work hard, but only the high ability workers. Only increasing $M$ and $\tilde{w}$ together, due to their complementarity, induces the low ability workers to work. However, the complementarity has little effect on the high ability types as they already work hard if either $M$ or $\tilde{w}$ is increased. We will exploit this reasoning on the identity of the marginally affected worker to differentiate our model's predictions from alternative interpretations.

Combining these arguments leads to several predictions which can be neatly summarized in Figure 1: 1) When the effect of output on the manager's payoff is small, the set of workers induced to exert effort by a high wage, relative to a low wage, will be the high ability (low effort cost) workers. 2) When the effect of output on the manager's payoff is larger, the set of workers induced to exert effort by a high wage, relative to a low wage, will be the low ability (high effort cost) workers. 3) These behavioral changes will be greatest among the most reciprocal workers. 


\subsection{Alternative Preference Specifications}

We are going to contrast these predictions with three other prominent approaches that have been used to organize observed behavior in gift exchange experiments: standard preferences (as a benchmark), social welfare preferences, as stressed by e.g. Charness and Rabin (2002), and inequity aversion following Fehr and Schmidt (1999).

Behavioral Predictions under Standard Preferences: The standard model of selfish preferences is a special case of the reciprocity model with $\eta=0$. Because our experiment has only flat wages (rather than outcome-contingent transfers), there is no way to induce a selfish worker with positive effort costs to choose $a_{2}$. Trivially therefore, increasing $M$ or $\tilde{w}$ will have no effect. This is summarized in Lemma 2.

Lemma 2 [Standard Preferences] $\gamma_{\text {Standard }}^{*}=0$ and the according comparative statics are trivially given by $\frac{\partial \gamma_{\text {standard }}^{*}}{\partial M}=0, \quad \frac{\partial \gamma_{\text {standard }}^{*}}{\partial \tilde{w}}=0, \quad \frac{\partial^{2} \gamma_{\text {standard }}^{*}}{\partial M \partial \tilde{w}}=0$.

Behavioral Predictions under Social Welfare Preferences: As stressed by e.g. Charness and Rabin (2002), social welfare preferences, i.e. the desire to increase social efficiency, might play a role in determining behavior. To capture this idea in a simple way, consider a worker who maximizes the weighted sum of his own utility and the manager's revenue,

$$
u_{S W}=\theta(u(\tilde{w})-\gamma c(a))+(1-\theta)(M \cdot E R(a)-\tilde{w})
$$

where $\theta \in[0,1]$ is the relative weight of the two components. Analogously to above consider the decision of a worker whether to work hard, i.e. choose $a_{2}$, or not. A worker will prefer to choose $a_{2}$ over $a_{1}$ if and only if

$$
\begin{aligned}
U_{S W}\left(a_{2}\right) & \geq U_{S W}\left(a_{1}\right) \\
-\theta \gamma c\left(a_{2}\right)+(1-\theta)\left(M \cdot E R\left(a_{2}\right)\right) & \geq-\theta \gamma c\left(a_{1}\right)+(1-\theta)\left(M \cdot E R\left(a_{2}\right)\right) \\
\frac{(1-\theta)}{\theta} \frac{M \cdot \Delta E R}{\Delta c} & \geq \gamma_{S W}^{*}
\end{aligned}
$$

We can immediately see that there is a strictly positive threshold for $\gamma_{S W}^{*}$ that is increasing in $M$ but independent of $\tilde{w}$ as it is only a transfer with no welfare implications. Hence there is no complementarity between $M$ and $\tilde{w}$.

Lemma 3 [Social Welfare Preferences] The critical value for working hard, $\gamma^{*}$, is strictly positive and defined by

$$
\frac{(1-\theta)}{\theta} \frac{M \cdot \Delta E R}{\Delta c}=\gamma_{S W}^{*} .
$$


$\gamma_{S W}^{*}$ increases in $M$ but not in $w$ and hence $M$ and $\tilde{w}$ are not complementary:

$$
\frac{\partial \gamma_{S W}^{*}}{\partial M}>0, \quad \frac{\partial \gamma_{S W}^{*}}{\partial w}=0, \quad \frac{\partial^{2} \gamma_{S W}^{*}}{\partial M \partial w}=0 .
$$

Behavioral Predictions with Inequity Aversion: Inequity aversion is perhaps the most prominent form of (outcome based) social preferences that has been employed to organize non-standard laboratory behavior. Using the formulation of inequity aversion (IA) by Fehr and Schmidt (1999) the worker's utility is given by

$$
u_{I A}=u(\tilde{w})-\gamma c(a)-\alpha \max [E R(a)-2 \tilde{w}+\gamma c(a), 0]-\beta \max [2 \tilde{w}-\gamma c(a)-E R(a), 0]
$$

where $\alpha$ weights unfavorable inequality and $\beta$ favorable inequality. ${ }^{9}$ For the parametrization of our experiment the manager is (almost) always better off, hence - to ease exposition we focus on this case. ${ }^{10}$

$$
u_{I A}=u(\tilde{w})-\gamma c(a)-\alpha \max [E R(a)-2 \tilde{w}+\gamma c(a), 0] .
$$

Analogously to above consider the decision of a worker whether to work hard, i.e. choose $a_{2}$, or not. A worker will prefer to choose $a_{2}$ over $a_{1}$ if and only if

$$
\begin{aligned}
U_{I A}\left(a_{2}\right) & \geq U_{I A}\left(a_{1}\right) \\
-\alpha\left[E R\left(a_{2}\right)-E R\left(a_{1}\right)\right] & \geq(1+\alpha) \gamma c\left(a_{2}\right)-(1+\alpha) \gamma c\left(a_{1}\right) \\
-\frac{\alpha \cdot M \cdot \Delta E R}{(1+\alpha) \Delta c} & \geq \gamma_{I A}^{*}
\end{aligned}
$$

There exists no positive value $\gamma_{I A}^{*}$ such that $a_{2}$ is induced and increasing $M$ decreases $\gamma_{I A}^{*}$ while the increase of $\tilde{w}$ has no effect. Hence $M$ and $\tilde{w}$ are not complements.

Lemma 4 [Inequity Aversion] There exists no positive value $\gamma_{I A}^{*}$ such that $a_{2}$ is induced:

$$
-\frac{\alpha \cdot M \cdot \Delta E R}{(1+\alpha) \Delta c}=\gamma_{I A}^{*} .
$$

Moreover, $\gamma_{I A}^{*}$ decreases in $M$ and is independent of $\tilde{w}$ :

$$
\frac{\partial \gamma_{I A}^{*}}{\partial M}<0, \quad \frac{\partial \gamma_{I A}^{*}}{\partial \tilde{w}}=0, \quad \frac{\partial^{2} \gamma_{I A}^{*}}{\partial M \partial \tilde{w}}=0 .
$$

\footnotetext{
${ }^{9}$ Given that we have only two actors, the formulation of Bolton and Ockenfels (2000) would give the same results.

${ }^{10}$ See Appendix A for a case where the worker is better off. In particular the comparative statics w.r.t. $\tilde{w}$ remain unchanged as compared to the present case.
} 


\subsection{Predictions}

Combining the results from our model and the three alternatives leads us to formulate the following three predictions that we test in our experimental analysis.

Prediction 1 When the effect of output on the manager's payoff is small, the effect on effort of a high wage relative to a low wage will be mainly driven by the high ability workers and not by the low ability workers.

Prediction 2 When the effect of output on the manager's payoff is larger, the effect on effort of a high wage relative to a low wage will be mainly driven by the low ability workers and not by the high ability workers.

Note that none of the other models predicts a differential effect of a high wage on the effort of high and low ability workers based on the manager's payoff. Nor does the workers' reciprocal inclination matter in any of these models, while it naturally does in our model.

Prediction 3 The above effects will be more pronounced among more reciprocal subjects.

\section{Experimental Results}

\subsection{Results}

Worker output was measured at 30-second intervals. We will use these high-frequency measurements, as well as the total output over the 25 minute task. We begin by considering the mean and median for the total number of questions answered in each treatment, presented in Table 1.

Offering a high wage increased output by almost 9.5 questions in the low payoff treatment, and by 13 questions in the high payoff treatment. Pooling the two payoff treatments, the effect of the wage offer on the raw means is marginally significant (ranksum test $\mathrm{p}=$ 0.0591). ${ }^{11}$ However, since individuals vary widely in ability, we will need to control for that

\footnotetext{
${ }^{11}$ Similarly, for managers the gross payoff (not including the wage payment) was higher with the $\$ 20$ wage: $\$ 47.51$ (low wage) vs. $\$ 48.01$ (high wage) in the low payoff treatment, and $\$ 46.82$ (low wage) vs. $\$ 50.26$ (high wage) in the high payoff treatment. Note, however, that the value of this increase in
} 


\section{Table 1: Mean Number of Correct Answers in the Coding Task}

\begin{tabular}{|c|c|c|c|}
\hline \multirow{2}{*}{\multicolumn{2}{|c|}{ Worker Wage }} & \multicolumn{2}{|c|}{ Manager Payoff } \\
\hline & & Low & High \\
\hline & Mean & 192.51 & 190.79 \\
\hline$\$ 10$ & $\mathrm{SD}$ & 48.20 & 66.58 \\
\hline & $\mathrm{N}$ & 43 & 53 \\
\hline & Mean & 201.95 & 203.94 \\
\hline$\$ 20$ & SD & 56.20 & 50.91 \\
\hline & $\mathrm{N}$ & 44 & 52 \\
\hline
\end{tabular}

Ranksum comparison of $\$ 20$ Wage vs $\$ 10$ Wage: $p=0.0591$.

Table 2: Performance by Quartiles of Baseline Speed

\begin{tabular}{|c|c|c|c|c|c|c|}
\hline \multicolumn{2}{|c|}{ Treatment } & \multicolumn{4}{|c|}{ Baseline Speed (Quartiles) } & \multirow{3}{*}{$\begin{array}{c}\text { Q4 - Q1 } \\
\text { Diff }\end{array}$} \\
\hline Worker & Manager & & & & & \\
\hline Wage & Payoff & {$[7,40]$} & {$[41,47]$} & {$[48,57]$} & {$[58,87]$} & \\
\hline$\$ 10$ & Low & 162.92 & 187.00 & 194.54 & 237.22 & 74.30 \\
\hline$\$ 20$ & Low & 131.73 & 192.20 & 219.00 & 258.83 & 127.11 \\
\hline$\$ 10$ & High & 146.50 & 176.86 & 189.56 & 256.14 & 109.64 \\
\hline$\$ 20$ & High & 167.25 & 190.50 & 210.11 & 253.00 & 85.75 \\
\hline
\end{tabular}

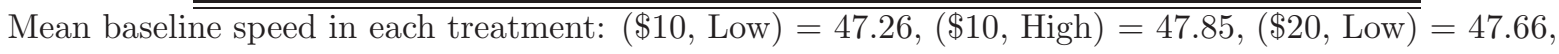
$(\$ 20$, High $)=47.96$.

to get a good estimate of the treatment effect. In Table 2, we show the mean output in each treatment for individuals in each quartile of performance in the piece rate coding task.

As one would imagine, individuals of higher ability performed better in the coding task than those with lower ability. Moreover, the individuals in the \$20 wage/high payoff treatment answer more questions than in the baseline $\$ 10$ wage/low payoff treatment for all ability quartiles. However, the impact of ability is different between the treatments. In the intermediate treatments - i.e. \$20 wage/low payoff and \$10 wage/high payoff the change productivity is less than the extra $\$ 10$ in wage payments, hence firms offering the low wage had the highest profit. 
in output between the lowest and highest quartiles is much larger than in the baseline or in the \$20 wage/high payoff treatment. The highest ability individuals answer substantially more correct answers in these treatments than in the baseline treatment, and look similar to the \$20 wage/high payoff treatment. This is already consistent with our Predictions 1 and 2 and is not predicted by the other models.

To that end, we allow in our specification for separate intercepts and speed coefficients in each treatment. We estimate using our high-frequency observations of effort (the number of correct answers per 30 -second interval) ${ }^{12}$. We run Random-Effects with a time trend, as well as Random-Effects with AR1 errors, and GLS with panel-specific AR1 errors and between-panel heteroskedasticity ${ }^{13}$.

The estimates for regressing the total number of correct answers are presented in Table 3. Both the \$20 wage/low payoff and $\$ 10$ wage/high payoff exhibit a significantly negative intercept and a significantly positive coefficient on speed (above and beyond the effect of speed in the baseline treatment). Thus, as can also be seen in the table of means, the lowest ability individuals performed somewhat worse, while higher ability individuals performed better than baseline when wages were raised. We find a small but insignificant effect at the median for the low payoff treatment (0.056 questions per 30 second, or 2.8 questions overall), but a significant positive effect for the high payoff treatment (0.08 questions per 30 seconds, or 4 questions overall). Figure 2 shows the estimated difference in output from offering a high wage within a payoff treatment at various speed percentiles. In the low payoff treatment, offering a high wage has a positive effect on high ability workers, and a negative effect on low ability workers. For the high payoff treatment, in contrast, offering a high wage has a positive effect on low ability workers, and a negligible effect on high ability workers (since they are already working hard even with a low wage). Both effects are positive but not significant at the median ability. The negative effect for low ability workers is not directly predicted by our theory, nor by any of the other models. However, we will argue in the discussion that it can be consistent with our model if we consider negative reciprocity.

\footnotetext{
${ }^{12}$ Estimating the same specification on Productivity $=$ \# Correct Answers $-0.25 *$ Mistakes yields quantitatively and qualitatively very similar results. Repeating the same exercise with total output over 25 minutes as dependent variable yields similar results, though less precisely estimated.

${ }^{13} \mathrm{~A}$ Wooldridge test for serial correlation finds autocorrelation $(p<0.01)$, and a Likelihood Ratio test suggests panel heteroscedasticity $(p<0.01)$.
} 
Table 3: Number of Correct Answers (per 30-second period)

\begin{tabular}{|c|c|c|c|}
\hline Coefficients & (1) & $(2)$ & (3) \\
\hline Baseline Speed & $\begin{array}{c}0.0332 * * * \\
(0.011)\end{array}$ & $\begin{array}{c}0.0332^{* * *} \\
(0.010)\end{array}$ & $\begin{array}{c}0.0455^{* * *} \\
(0.0037)\end{array}$ \\
\hline Wage $=\$ 20$ & $\begin{array}{c}-1.704^{* * *} \\
(0.61)\end{array}$ & $\begin{array}{c}-1.692^{* * *} \\
(0.65)\end{array}$ & $\begin{array}{c}-1.400^{* * *} \\
(0.20)\end{array}$ \\
\hline Manager Payoff High & $\begin{array}{c}-2.281^{* * *} \\
(0.69)\end{array}$ & $\begin{array}{c}-2.276^{* * *} \\
(0.64)\end{array}$ & $\begin{array}{c}-1.624^{* * *} \\
(0.21)\end{array}$ \\
\hline (\$20 Wage) X (High Payoff) & $\begin{array}{c}2.607^{* * *} \\
(0.88)\end{array}$ & $\begin{array}{c}2.583^{* * *} \\
(0.89)\end{array}$ & $\begin{array}{c}2.037^{* * *} \\
(0.30)\end{array}$ \\
\hline (\$20 Wage) X Speed & $\begin{array}{c}0.0383^{* * *} \\
(0.013)\end{array}$ & $\begin{array}{c}0.0381^{* * *} \\
(0.013)\end{array}$ & $\begin{array}{c}0.0310^{* * *} \\
(0.0042)\end{array}$ \\
\hline (High Payoff) X Speed & $\begin{array}{c}0.0454^{* * *} \\
(0.014)\end{array}$ & $\begin{array}{c}0.0453^{* * *} \\
(0.013)\end{array}$ & $\begin{array}{c}\left.0.0357^{* * *}\right) \\
(0.0045)\end{array}$ \\
\hline (\$20 Wage) X (High Payoff) x Speed & $\begin{array}{c}-0.0516^{* * *} \\
(0.018)\end{array}$ & $\begin{array}{c}-0.0513^{* * *} \\
(0.018)\end{array}$ & $\begin{array}{c}-0.0428^{* * *} \\
(0.0061)\end{array}$ \\
\hline Period & $\begin{array}{c}0.0574 * * * \\
(0.0040)\end{array}$ & & \\
\hline Period $^{2}$ & $\begin{array}{c}-0.000758^{* * *} \\
(0.000074)\end{array}$ & & \\
\hline Demographic Dummies & YES & YES & YES \\
\hline Panel Structure & Rand. Eff. & Rand. Eff. & Heterosked. \\
\hline Time-Error Structure & Time Trend & AR-1 & AR-1 \\
\hline Constant & $\begin{array}{l}1.915^{*} \\
(0.98) \\
\end{array}$ & $\begin{array}{c}2.749^{* * *} \\
(1.01) \\
\end{array}$ & $\begin{array}{c}2.354^{* * *} \\
(0.29) \\
\end{array}$ \\
\hline Observations & 9300 & 9300 & 9300 \\
\hline Number of subjects & 186 & 186 & 186 \\
\hline
\end{tabular}


Figure 2: Wage Effect - 30sec intervals

Predicted Wage Effect (\$20 - \$10)

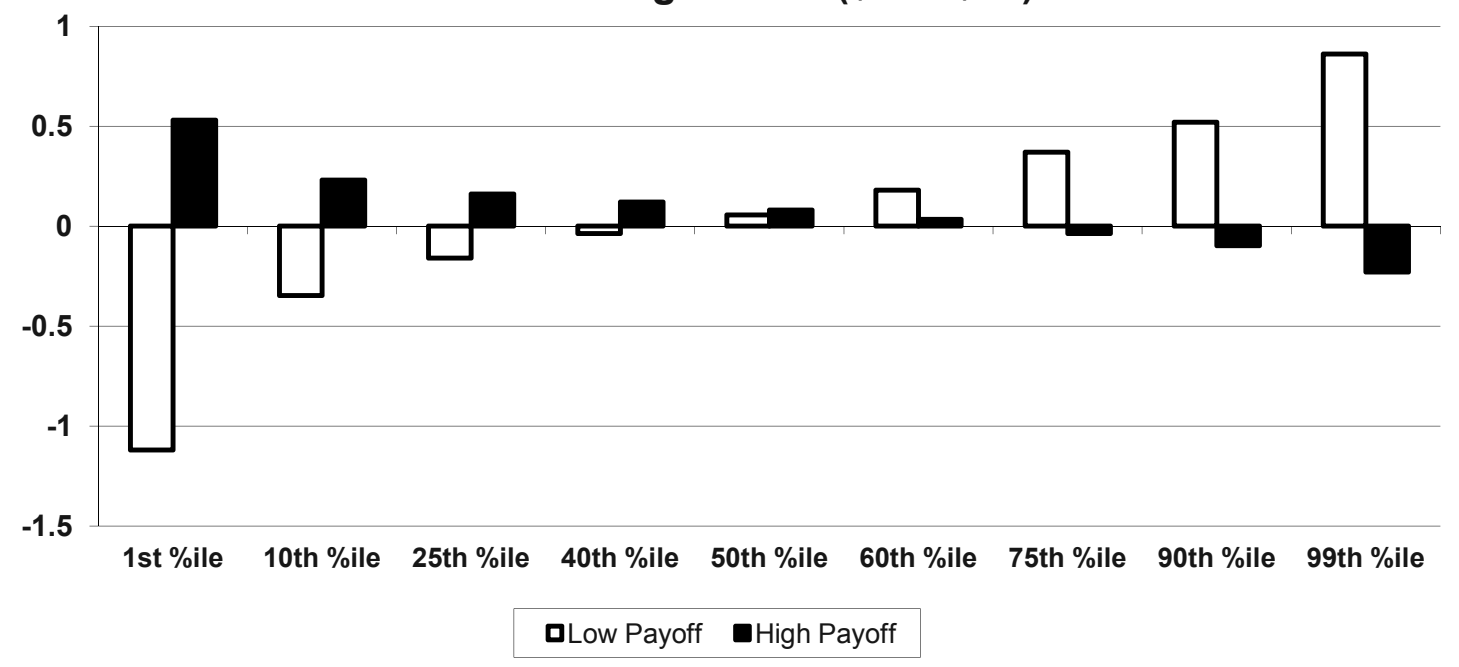

All predicted wage effects for the Low Payoff condition are significant except for the 40th and 50th percentiles. All predicted wage effects for the High Payoff condition at the 50th percentile and below are significant. All differences between the payoff conditions are significant except for the 50th percentile.

We also relax the linearity assumption by estimating a specification with dummies for each tercile of baseline speed. ${ }^{14}$ Our results from above are qualitatively unchanged. Table 6 in Appendix B presents this regression.

Figure 3 presents the estimated wage effects for the low and high payoff treatments for each of the three ability groups. As in our linear specification we find that in the low payoff treatment, there is a negative effect of the wage on the lowest ability workers, and a positive effect on higher ability workers. In the high payoff condition, in contrast, we find that the largest wage effect is among low ability workers; with a smaller positive effect among moderate ability workers and a small negative effect among high ability workers. As before, the small/negative treatment effect among high ability workers is because almost all of the workers with high ability are exerting effort across different treatments. Taking the average treatment effect for the whole sample, we actually find a significant negative effect in the low payoff treatment ( -0.34 questions per 30 seconds, or 17 questions over the whole task) - driven by the above mentioned negative response of the low ability workers. In the high payoff treatment we find a significant positive effect overall (0.44 questions

\footnotetext{
${ }^{14}$ We choose three groups so that later when we separate out subjects with different preference types we have enough subjects in each ability-preference category to generate good estimates.
} 


\section{Figure 3: Wage Effect with Ability Dummies}

Wage Effects $(\$ 20-\$ 10)$

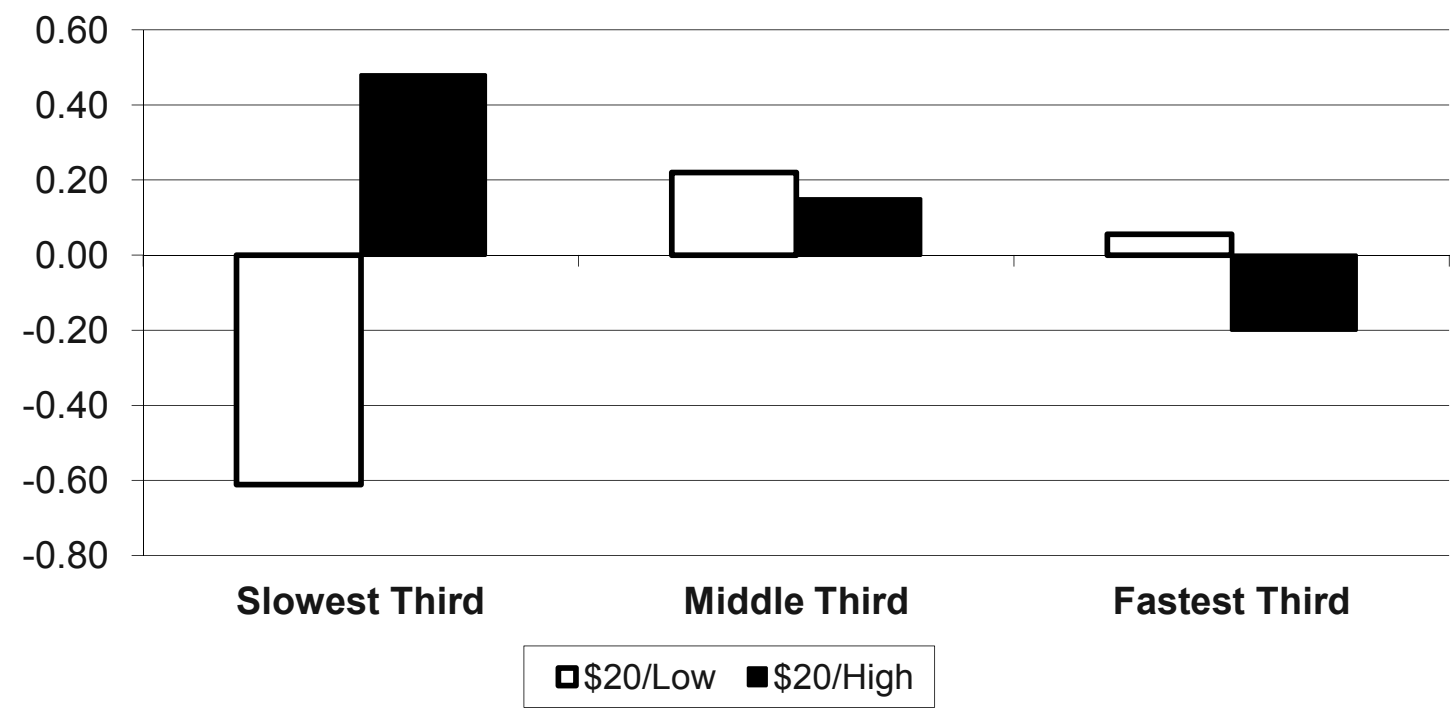

Predicted wage effects for the Low Payoff condition are significant for the slowest and middle terciles of speed. All predicted wage effects for the High Payoff condition are significant. Differences between the payoff conditions are significant for the slowest and fastest speed terciles.

per 30 seconds, or 22 questions over the whole task). The difference between the payoff treatments is also significant.

While our results accord with the predictions of our reciprocity model, we want to further strengthen the case that the observed gift-exchange represents "reciprocity". To that end, we look to the results from our trust game to identify those individuals who are most likely to be reciprocal types. We should expect that our experimental sample is a mix of "selfish" subjects and "reciprocal" subjects, and that treatment manipulations have a stronger effect on the more reciprocal subjects. Therefore, if we can focus the estimates of the treatment effect on the reciprocal subjects, then the estimated treatment effects should be larger (since they will not be averaged with the subjects who exhibit no treatment effects).

In the trust game we have all subjects specify an amount to return to the sender for each possible sender decision. This gives us a complete return function for all subjects. The literature on reciprocity generally considers an upwards-sloping return function (i.e. the subject returns a larger amount when the sender has been more trusting/generous) to be indicative of positive reciprocity. For example, Camerer and Fehr (2004) describe the 
standard results in the literature as follows: "The amount trustees repay increases with y [the amount sent], which can be interpreted as positive reciprocity, or a feeling of obligation to pay more to an investor who has exhibited trust". ${ }^{15}$ Since subjects' decisions are largely (but not completely) monotonic, we will use as our measure of reciprocity the difference between the largest and smallest fraction returned to the sender. ${ }^{16}$ Very similar results may be obtained by using the difference between the $\$ 1$ and $\$ 10$ decision, or by using the slope of the linear fit to the return function. On average responders return an approximately constant fraction of the amount sent - between $30 \%$ and $35 \%$ (except when $\$ 1$ is sent, when responders return 26\%). At the subject level, thirty percent of subjects return a constant fraction, and the median difference between the smallest fraction returned and the largest fraction returned is $22 \%$.

One may be concerned that the coding task may have influenced decisions in the trust game. However, our results there are very similar to the results in the literature, e.g. in Ashraf et al. (2006). Moreover, the distribution of the reciprocity measure is not different between the treatments (regressing the reciprocity measure on treatment dummies yields p-values $>0.5$ for each treatment.). ${ }^{17}$

\footnotetext{
${ }^{15}$ Ashraf et al. (2006) have subjects play both a trust game and a dictator game, and find that for subjects in the US the increasing slope of the return function cannot be fully explained by distributional preferences, suggesting reciprocity distinctly related to positive actions by the first mover as an explanation.

${ }^{16} \mathrm{In}$ our experiment, on average the difference was 0.23 with a standard deviation of 0.197 , a minimum of 0 , and a maximum of 0.81 .

${ }^{17}$ Note that even if one task influenced the other, it would still suggest that the two tasks are measuring the same aspect of social preferences, i.e. the same mechanism driving the behavior.
} 
Table 4: Effects of Reciprocity

\begin{tabular}{|c|c|c|c|c|c|c|}
\hline \multirow[b]{2}{*}{ Coefficients } & \multicolumn{2}{|r|}{ (1) } & \multicolumn{4}{|c|}{ Composite Coefficients } \\
\hline & & X (Max - Min) & 33rd \%ile & 50 th \%ile & 60 th \%ile & 75th \%ile \\
\hline \multirow[t]{2}{*}{ Baseline Speed } & $0.0516^{* * *}$ & -0.0269 & & & & \\
\hline & $(0.0058)$ & $(0.019)$ & & & & \\
\hline \multirow[t]{2}{*}{ Wage $=\$ 20$} & $-1.373^{* * *}$ & -0.518 & $-1.456^{* * *}$ & $-1.488^{* * *}$ & $-1.508^{* * *}$ & $-1.555^{* * *}$ \\
\hline & $(0.33)$ & $(1.04)$ & $(0.22)$ & $(0.20)$ & $(0.20)$ & $(0.22)$ \\
\hline \multirow[t]{2}{*}{ Manager Payoff High } & -0.378 & $-4.228^{* * *}$ & $-1.055^{* * *}$ & $-1.308^{* * *}$ & $-1.478^{* * *}$ & $-1.858^{* * *}$ \\
\hline & $(0.39)$ & $(1.18)$ & $(0.26)$ & $(0.23)$ & $(0.22)$ & $(0.24)$ \\
\hline \multirow[t]{2}{*}{ (\$20 Wage) X (High Payoff) } & $0.971^{*}$ & $4.006^{* *}$ & $1.612^{* * *}$ & $1.852^{* * *}$ & $2.013^{* * *}$ & $2.374^{* * *}$ \\
\hline & $(0.54)$ & $(1.65)$ & $(0.35)$ & $(0.31)$ & $(0.29)$ & $(0.32)$ \\
\hline \multirow[t]{2}{*}{ (\$20 Wage) X Speed } & $0.0290^{* * *}$ & 0.0151 & $0.0314^{* * *}$ & $0.0323^{* * *}$ & $0.0329^{* * *}$ & $0.0343^{* * *}$ \\
\hline & $(0.007)$ & $(0.022)$ & $(0.0046)$ & $(0.0042)$ & $(0.0041)$ & $(0.0046)$ \\
\hline \multirow[t]{2}{*}{ (High Payoff) X Speed } & 0.0116 & $0.0813^{* * *}$ & $0.0246^{* * *}$ & $0.0295^{* * *}$ & $0.0327 * * *$ & $0.0401^{* * *}$ \\
\hline & $(0.0081)$ & $(0.025)$ & $(0.0053)$ & $(0.0047)$ & $(0.0046)$ & $(0.0049)$ \\
\hline \multirow[t]{2}{*}{ (\$20 Wage) X (High Pay.) X Spd. } & $-0.0185^{*}$ & $-0.0925^{* * *}$ & $0.0333^{* * *}$ & $-0.0388^{* * *}$ & $-0.0426^{* * *}$ & $-0.0509^{* * *}$ \\
\hline & $(0.011)$ & $(0.033)$ & $(0.0071)$ & $(0.0062)$ & $(0.0060)$ & $(0.0064)$ \\
\hline \multirow[t]{2}{*}{ Max \% Return - Min \% Return } & 1.247 & & & & & \\
\hline & $(0.86)$ & & & & & \\
\hline Demographic Dummies & YES & & & & & \\
\hline \multirow[t]{2}{*}{ Constant } & $2.127^{* * *}$ & & & & & \\
\hline & $(0.41)$ & & & & & \\
\hline Observations & 9300 & & & & & \\
\hline Number of Subjects & 186 & & & & & \\
\hline
\end{tabular}

The first column reports main effects of treatment variables. The second column reports the coefficients for the interaction between the treatment variables and the reciprocity measure. The last four columns reports the total coefficient at various quantiles of reciprocity. The reciprocity measure for each reported quantile: $0.15,0.22,0.26,0.35$. Specification includes heteroskedastic and panel level AR-1 errors. Standard errors are reported in parentheses. Significance is denoted: ${ }^{*} p<0.10 * * p<0.05 * * * p<0.01$. Demographic dummies include dummy variables for gender, race, age, work experience, and student status. 
Table 4 presents results when we also calculate total treatment coefficients evaluated at various levels of reciprocity, reported in the last four columns. This indicates the magnitude of the treatment effect for a subject with a reciprocity type of varying levels. Note that all of the treatment coefficients increase in level as reciprocity increases, particularly the coefficients in the high payoff treatment. This suggests that while there is some small underlying level of gift-exchange for selfish types, the majority of the substantial gift exchange we observe in the high payoff treatment for the full sample is being driven by high reciprocity types. The effect of reciprocity can also be seen if we instead use a dummy denoting subjects with a high measure of reciprocity (in particular, above the 66th percentile), and dummies for ability groups. Table 7 in Appendix B presents this regression.

To see the effect of reciprocal preferences, Figure 4 presents the estimated effects of offering a higher wage for the low and high payoff treatments respectively. In the low payoff treatment low-reciprocity subjects of all ability levels exhibit a negative response to the high wage offer, while medium and high ability subjects with high reciprocity respond positively. The overall effect is significant for low reciprocity workers $(-0.27$ questions per 30 seconds, or 13.5 questions overall), while the effect is insignificant for high reciprocity workers (0.09 questions per 30 seconds). The difference in between the low and high reciprocity subjects is significant (0.36 questions per 30 seconds, or 18 questions for the whole task). For the high payoff treatment both low-reciprocity and high-reciprocity types show a positive response among low ability types; however the high reciprocity types have a positive response among middle ability subjects, and a negative response among high ability subjects. Both groups show a positive overall effect of the wage increase (0.19 and 0.24 questions per 30 seconds, or 9.5 and 12 questions overall), with the difference being positive but not significant. Taken together, this confirms our Prediction 3.

Though real firms typically will not use information from an experimental trust game when hiring workers, personality tests are quite common in the hiring practices of firms (cf. Autor and Scarborough, 2008). Thus, we now look to the results of the Big-5 Personality Test which we had subjects complete at the end of the experiment.

We then identify subjects who score highly on the trait "agreeableness", which has been shown experimentally to relate to reciprocity (see Ben-Ner et al. 2004, Ashton et al. 1997). ${ }^{18}$ High agreeableness corresponds with one of the criteria Autor and Scarborough

\footnotetext{
${ }^{18}$ While Ben-Ner et al. (2004) and Ashton et al. (1997) also find some evidence that "openness" and "emotional stability" may relate to reciprocity as well, the relationship between reciprocity and agreeable-
} 


\section{Figure 4: Wage Effects with Reciprocity Dummies}

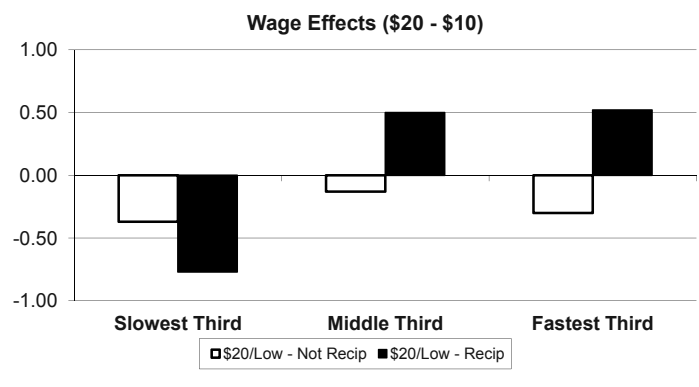

(a) Low Manager Payoff

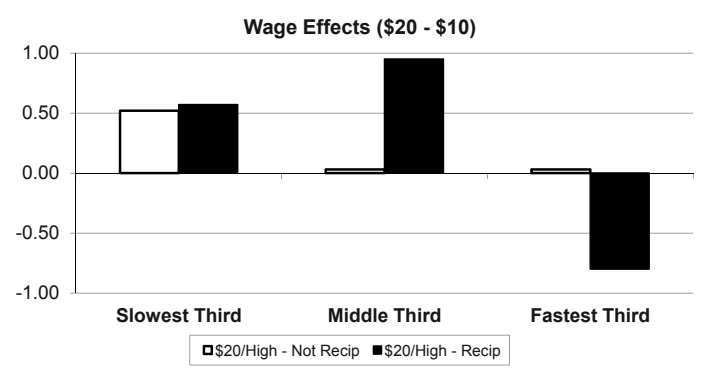

(b) High Manager Payoff

Predicted wage effects for the Low Payoff condition are significant except for the middle speed tercile of low reciprocity workers. Predicted wage effects for the High Payoff condition are significant except for the middle and fastest speed terciles of low reciprocity workers. Differences between low and high reciprocity workers are significant except for the slowest speed tercile in the High Payoff condition.

identify in the hiring practice of the firm they study. ${ }^{19}$

We begin by regressing our reciprocity measure on the z-scores for the five personality traits. $^{20}$ The results are presented in Table 8 in Appendix B. In accordance with the previous literature we find a (marginally) significant positive relationship between reciprocity and agreeableness.

To identify the differing treatment effect among high agreeableness subjects we define a dummy variable denoting if a subject is above the 66th percentile in agreeableness. We then estimate our output regression interacting all of the treatment variables with the personality dummy. The results are presented in Table 5. As with reciprocity, subjects with high agreeableness exhibit treatment effects of greater magnitude, suggesting they are driving a substantial portion of our effect. Given the significant positive relationship between reciprocity and agreeableness it should not be surprising that the results here parallel the results we obtained using the information from the experimental trust game.

ness was most robust across specification and sample.

${ }^{19}$ The firm gave hiring preference to applicants with positive z-scores for agreeableness, conscientiousness, and extroversion.

${ }^{20}$ Each subject's raw score was calculated based on the sum of their self-ratings for each trait. A few subjects skipped one of the questions; their raw score was rescaled by 10/9; our results do not qualitatively change if we exclude these subjects. The raw scores for each trait were than standardized to have mean 0 and standard deviation 1 . 
Table 5: Effect of Agreeableness (as a Proxy for Reciprocity)

\begin{tabular}{|c|c|c|c|}
\hline \multirow[b]{2}{*}{ Coefficients } & \multicolumn{2}{|r|}{ (1) } & Composite \\
\hline & & X Agreeable & if Agreeable \\
\hline \multirow[t]{2}{*}{ Baseline Speed } & $0.0435^{* * *}$ & 0.00253 & \\
\hline & $(0.0048)$ & $(0.0075)$ & \\
\hline \multirow[t]{2}{*}{ Wage $=\$ 20$} & $-1.297^{* * *}$ & $-0.839^{* *}$ & $-2.137^{* * *}$ \\
\hline & $(0.25)$ & $(0.43)$ & $(0.33)$ \\
\hline \multirow[t]{2}{*}{ Manager Payoff High } & $-1.053^{* * *}$ & $-1.334^{* * *}$ & $-2.387 * * *$ \\
\hline & $(0.28)$ & $(0.44)$ & $(0.34)$ \\
\hline \multirow[t]{2}{*}{ (\$20 Wage) X (High Payoff) } & $1.798^{* * *}$ & $0.965^{*}$ & $2.763^{* * *}$ \\
\hline & $(0.37)$ & $(0.56)$ & $(0.31)$ \\
\hline \multirow[t]{2}{*}{ (\$20 Wage) X Speed } & $0.0300^{* * *}$ & 0.0139 & $0.0439^{* * *}$ \\
\hline & $(0.0055)$ & $(0.0089)$ & $(0.0067)$ \\
\hline \multirow[t]{2}{*}{ (High Payoff) X Speed } & $0.0281^{* * *}$ & $0.0189^{* *}$ & $0.0470 * * *$ \\
\hline & $(0.0061)$ & $(0.0091)$ & $(0.0069)$ \\
\hline \multirow[t]{2}{*}{ (\$20 Wage) X (High Pay) X Spd. } & $-0.0421^{* * *}$ & -0.0109 & $-0.0530 * * *$ \\
\hline & $(0.0078)$ & $(0.011)$ & $(0.0083)$ \\
\hline \multirow[t]{2}{*}{ Agreeable Highest Third } & -0.0512 & & \\
\hline & $(0.35)$ & & \\
\hline Demographic Dummies & YES & & \\
\hline \multirow[t]{2}{*}{ Constant } & $2.105^{* * *}$ & & \\
\hline & $(0.32)$ & & \\
\hline Observations & 9300 & & \\
\hline Number of Subjects & 186 & & \\
\hline
\end{tabular}

The first column reports main effects of treatment variables. The second column reports the coefficients for the interaction between the treatment variables and the agreeableness proxy for reciprocity. The dummy for high agreeableness denotes subjects whose agreeableness score is at the 66th percentile or higher. Specification includes heteroskedastic and panel level AR-1 errors. Standard errors are reported in parentheses. Significance is denoted: ${ }^{*} p<0.10^{* *} p<0.05^{* * *} p<0.01$. Demographic dummies include dummy variables for gender, race, age, work experience, and student status. 
Figure 5: Wage Effects with Personality Test Dummies

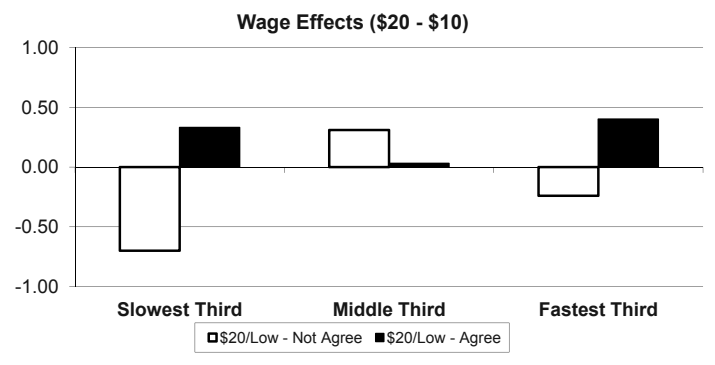

(a) Low Manager Payoff

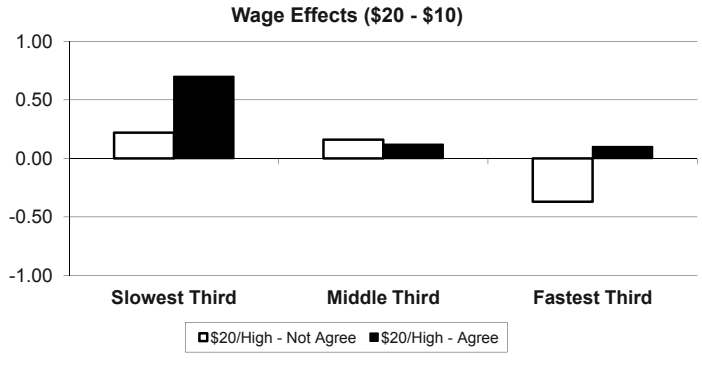

(b) High Manager Payoff

Predicted wage effects for the Low Payoff condition are significant except for the slowest and middle speed tercile of high agreeableness workers. Predicted wage effects for the High Payoff condition are significant except for the middle tercile of low agreeableness workers and the middle and fastest speed terciles of high agreeableness workers. Differences between low and high agreeableness workers are significant except for the middle speed terciles in each payoff condition.

To better understand the differences between low and high agreeableness subjects, we again estimate a specification with dummies for low, middle and high ability workers. The results are presented in Table 9 in Appendix B.

Figure 5 presents the effects of offering a high wage on output for low and high agreeableness workers in the low and high payoff treatments respectively. In the low payoff treatment, the low agreeableness workers have a significantly negative response among low and high ability workers; the overall effect is also negative -0.21 questions per 30 seconds, or -10.5 questions for the whole task. High agreeableness workers, however, have a positive response for all ability levels, with significance in the high ability group. The overall effect of offering the high wage is positive ( 0.25 questions per 30 seconds, or 12.5 questions over the whole task), and the difference between the low and high agreeableness workers is positive and significant ( 0.46 questions per 30 seconds, or 23 questions overall). Similarly, in the high payoff treatment, highly agreeable workers are affected more positively by the high wage offer, with non-agreeable workers showing no positive response $(0.0033$ questions per 30 seconds for low agreeableness workers, 0.31 questions per 30 seconds for high agreeableness workers - 15.5 questions overall). The overall difference between low and high agreeableness workers is also significant (0.30 questions per 30 seconds). 


\subsection{Discussion}

Revisiting our predictions, we find several points supporting our reciprocity-based model. We find an increase in output when subjects are paid a high wage by their manager and this increase is larger and more significant when the manager has a larger benefit from high effort. We also find that the strongest increase in effort in the low payoff treatment was among high ability workers, while the strongest increase in the high payoff treatment was among low ability workers. This accords with our prediction that increasing the value of output to the manager should make the marginal worker induced to exert effort to be a lower ability worker, since high ability workers may exert effort even without the high wage. We also find evidence that subjects that can be identified as reciprocal will exhibit a more positive response of their effort from a high wage offer. We can identify these subjects either directly via a trust game, or indirectly via a personality test. This latter finding points at a wider applicability of our results as personality tests are a prominent element in firms' hiring procedures. Their usage may point at firms using reciprocal motivations and tailoring their incentive and organizational structure to get the most mileage out of them. In Englmaier and Leider (2008) we follow this reasoning and find suggestive evidence for this kind of firm behavior.

As in many previous studies, standard preferences do not explain behavior well in our experiment, since the standard model predicts no change in effort for any of our treatments. Additionally, social welfare preferences, while predicting a positive effort response to an increase in the effect of output on the manager's payoff, fail to explain the positive response to an increase in the wage and the differential effects of the treatments on the different ability types. Inequity aversion, rather than reciprocity, has often been used to model gift-exchange in studying agency problems. However, inequity aversion has significant limitations in modeling gift-exchange. With weak or no monetary incentives, social preferences in the form of inequity aversion will only induce the worker to exert effort if either 1) effort reduces the worker's advantageous inequality, i.e. if the worker begins with a larger payoff than the manager and the manager receives $>50 \%$ of the profit from the worker's effort OR 2) effort reduces the worker's disadvantageous inequality, i.e. the worker begins with a smaller payoff than the manager and the worker receives $>50 \%$ of the profit from his own effort. Moreover, the introduction of a high wage will only induce excess effort if it creates (or exacerbates) one of these conditions. Typically lab gift-exchange games operate under the first setup. If the manager offers a low wage, then the manager and the 
worker will have relatively equal payoffs if the worker does not work, and the manager will be enriched by effort. If the manager offers a high wage, then the worker will have a much higher payoff if he does not work, but can bring up the manager's payoff to be more equal if he does work.

In our experiment, however, in the low payoff treatment neither of these conditions is true. For both the low and high wage, the manager has a higher payoff than the worker, and when the worker works hard he only further increases the inequality. Therefore, inequity aversion could not be causing the worker to work hard, and if anything should cause the worker to purposefully answer questions incorrectly to lower the manager's payoff. Moreover, since the marginal effect of effort on inequality is the same under the low and high wage, under the standard Fehr-Schmidt preferences for inequity aversion, the effect of this form of social preferences should be the same regardless of the wage. Moreover, since the effort of higher ability workers will increase inequality by a greater amount, they should be less likely to work hard in both wage conditions. For the high payoff treatments, while the high wage case is in general ambiguous (since for less than 150 correct answers the worker has a higher payoff than the manager) the vast majority of workers (88\%) answer enough questions correctly that the manager will have a higher payoff, and more than half (57\%) answer enough questions that the manager's payoff is at least $\$ 10$ larger than theirs. Moreover, in the low wage condition, the worker will be at a disadvantage if he answers at least 50 questions correctly (which all but one worker does), and $88 \%$ answer enough questions that the manager has at least a $\$ 10$ higher payoff than the worker. However, the higher value of correct answers to the manager, and in particular the higher impact of effort for high ability workers, should mean that inequity averse workers work less hard (especially high ability ones). Hence, inequity aversion does not explain the treatment effects in our experiment.

As mentioned above, the negative effect of a wage increase for low ability workers is not directly predicted by our theory, nor any of the other models, however it can be consistent with the model if we consider negative reciprocity. In our basic model reciprocity can only have positive effects, since the contract must meet the worker's individual rationality constraint - i.e. he has to be willing to accept the contract because it is better than his outside option. In our experiment, however, the worker did not have the ability to choose an outside option. Low ability workers may interpret a high wage (given low payoffs) from the manager as indicative of high expectations of output to justify the wage. In fact, if low 
ability means high cost of effort, then the low ability worker may feel that the manager's expectations for his effort/output are too high. That is, he may believe that the manager expects such a high effort that the worker's utility is in fact negative. This may lead the worker to shirk so that the manager is "punished". Similarly, high payoffs may also lead the workers to believe the manager expects great effort and output (since it is so valuable to the manager). Moreover, if we use Productivity =\# Correct Answers - 0.25* Mistakes as dependent variable the overall adverse effect, driven by the lowest workers, of a wage increase is moderated and no longer significant, casting some doubt on the stability of this effect. See Appendix ?? for a comparison of the most relevant calibrations for both output measures.

\section{Conclusion}

The importance of fairness and social preferences for the work relation has long been documented. Based on our earlier work, Englmaier and Leider (2008), we argue that a key determinant of the effectiveness of using reciprocal motivations to provide incentives is the ability of a worker to repay a gift, i.e. the magnitude of the manager's benefit from high effort is crucial to gift-exchange. We test our model in the lab by manipulating the extent to which the manager benefits from worker effort. In the experiment we find that the manager's benefit has important effects on behavior: we observe positive gift exchange when the manager directly benefits from worker output. We collect additional data so we can identify the non-trivial role workers' abilities play in determining individual responses to an initial gift. Furthermore, we can identify reciprocal subjects from their trust game responses, and show that they exhibit a greater response to a high wage. We also use standard personality tests to classify types as reciprocal and get comparable results.

Our study indicates that employing workers' reciprocity to provide incentives is a viable alternative and can be successfully done. However, if a firm wishes to use reciprocal incentives, it may be important that various complementary parts of the firm's compensation and HR policy are coordinated to maximize the effect of reciprocity. Our experimental results suggest that a firm hoping to induce a gift-exchange with its workers may be most successful when the worker's manager directly benefits from worker effort, and when workers have been selected at hiring to be highly reciprocal. 
Our study is an early step towards more fully exploring this topic, and there are many fruitful directions for future research. For example, further empirical work can explore the optimal magnitude of the wage gift and the proper mix between reciprocal and explicit motivation to maximize the profitability of gift exchange. Our theoretical model suggests that a job where explicit incentives work poorly due to a noisy production function, and where output is highly valuable to the manager is the environment where reciprocal incentives should be most attractive.

\section{References}

1. Akerlof, G.A. (1982) "Labor contracts as a partial gift exchange," Quarterly Journal of Economics, Vol. 97(4), pp. 543-569

2. Ashraf, N., I. Bohnet, and N. Piankov (2006) "Decomposing trust and trustworthiness," Experimental Economics, Vol. 9(3), pp. 193-208

3. Ashton, M.C., S.V. Paunonen, E. Helmes, and D.N. Jackson (1998) "Kin Altruism, Reciprocal Altruism, and the Big Five Personality Factors," Evolution and Human Behavior, Vol. 19, pp. 243-255

4. Autor, D.H. and D. Scarborough (2008) "Does Job Testing Harm Minority Workers? Evidence from Retail Establishments," Quarterly Journal of Economics, Vol. 123(1), pp. $219-277$

5. Ben-Ner, A., F. Kong, and L. Putterman (2004a) "Share and share alike? Gender-pairing, personality, and cognitive ability as determinants of giving," Journal of Economic Psychology, Vol. 25(5), pp. 581-589

6. Ben-Ner, A., L. Putterman, F. Kong, and D. Magan (2004b) "Reciprocity in a two-part dictator game," Journal of Economic Behavior 85 Organization, Vol. 53(3), pp. 333-352

7. Bolton, G.E. and A. Ockenfels (2000) "ERC - A Theory of Equity, Reciprocity and Competition," American Economic Review, Vol. 90(1), pp. 166-193

8. Camerer, C.F. and E. Fehr (2004) "Measuring Social Norms and Preferences using Experimental Games: A Guide for Social Scientists," In J. Henrich et al. (eds.) Foundations of Human Sociality: Economic Experiments and Ethnographic Evidence from Fifteen Small-Scale Societies (Oxford: Oxford University Press)

9. Charness, G., and Rabin, M. (2002) "Understanding Social Preferences with Simple Tests," Quarterly Journal of Economics, Vol. 117, pp. 817-869

10. Dufwenberg, M. and G. Kirchsteiger (2004) "A Theory of Sequential Reciprocity," Games and Economic Behavior, Vol. 47, pp. 268-98

11. Englmaier, F. and S. Leider (2008) "Contractual and Organizational Structure with Reciprocal Agents," CESifo Workingpaper 2415 
12. Falk, A. (2007) "Gift Exchange in the Field," Econometrica, Vol. 75(5), pp. 1501-1511

13. Falk, A. and U. Fischbacher (2006) "A Theory of Reciprocity," Games and Economic Behavior, Vol. 54(2), pp. 293-315

14. Fehr, E. and A. Falk (2008) "Reciprocity in Experimental Markets," in HandBook of Experimental Economic Results, C.R. Plott and V.L. Smith, eds.

15. Fehr, E., S. Gaechter, and G. Kirchsteiger (1997) "Reciprocity as a Contract Enforcement Device," Econometrica, Vol. 65, pp. 833-860

16. Fehr, E. and S. Gaechter (2000) "Fairness and Retaliation - The Economics of Reciprocity," Journal of Economic Perspectives, Vol. 14, pp. 159-181

17. Fehr, E. and K.M. Schmidt (1999) "A Theory of Fairness, Competition and Cooperation," Quarterly Journal of Economics, Vol. 114(3), pp. 817-868

18. Fehr, E. and K.M. Schmidt (2003) "Theories of Fairness and Reciprocity - Evidence and Economic Applications" in M. Dewatripont et.al.(eds.) Advances IN ECONOMics AND Econometrics, Eighth World Congress of the Econometric Society, Vol. 1 (Cambridge: Cambridge University Press), pp. 208-257

19. Gneezy, U. and J. List (2006) "Putting Behavioral Economics to Work: Field Evidence on Gift Exchange," Econometrica, Vol. 74(5), pp. 1365-1384

20. Henning-Schmidt, H., B. Rockenbach, and Sadrieh, A. (2008) "In Search of Workers' Real Effort Reciprocity - A Field and a Laboratory Experiment," Journal of the European Economic Association, forthcoming.

21. Irlenbusch, B. and D. Sliwka (2005) "Transparency and reciprocal behaviour in employment relations," Journal of Economic Behavior 63 Organization, Vol. 56, pp. 383-403

22. Maximiano, S., R. Sloof, and J. Sonnemans (2007) "Gift Exchange in a Multi-Worker Firm," The Economic Journal, Vol. 117, pp. 1025-1050

23. Rabin, M. (1993) "Incorporating Fairness into Game Theory and Economics," American Economic Review, Vol. 83 (5), pp. 1281-1302 


\section{A Alternative Predictions}

Using the formulation of inequity aversion (IA) by Fehr and Schmidt (1999) and, in contrast to the main part of the paper, focussing on the case where the worker is better off, the worker's utility is given by

$$
u_{I A}=u(\tilde{w})-\gamma c(a)-\beta[2 \tilde{w}-\gamma c(a)-E R(a)]
$$

Analogously to above consider the decision of a worker whether to work hard, i.e. choose $a_{2}$, or not. A worker will prefer to choose $a_{2}$ over $a_{1}$ if and only if

$$
\begin{aligned}
U_{I A}\left(a_{2}\right) & \geq U_{I A}\left(a_{1}\right) \\
u(\tilde{w})-(1-\beta) \gamma c\left(a_{2}\right)-\beta\left[2 \tilde{w}-E R\left(a_{2}\right)\right] & \geq u(\tilde{w})-(1-\beta) \gamma c\left(a_{1}\right)-\beta\left[2 \tilde{w}-E R\left(a_{1}\right)\right] \\
\frac{\beta \cdot M \cdot \Delta E R}{(1-\beta) \Delta c} & \geq \gamma_{I A}^{*} .
\end{aligned}
$$

Lemma 5 [Inequity Aversion ( $\beta)$ ] There exists a positive value $\gamma_{I A}^{*}$ such that $a_{2}$ is induced:

$$
\frac{\beta \cdot M \cdot \Delta E R}{(1-\beta) \Delta c}=\gamma_{I A}^{*}
$$

Moreover, $\gamma_{I A}^{*}$ increases in $M$ and is independent of $w$ :

$$
\frac{\partial \gamma_{I A}^{*}}{\partial M}>0, \quad \frac{\partial \gamma_{I A}^{*}}{\partial w}=0, \quad \frac{\partial^{2} \gamma_{I A}^{*}}{\partial M \partial w}=0
$$




\section{B Additional Tables}

Table 6: Number of Correct Answers (per 30-second period)

\begin{tabular}{lc}
\hline \hline Coefficients & $(\mathbf{1})$ \\
\hline \hline Slowest Third & $-0.256^{* * *}$ \\
& $(0.074)$ \\
Fastest Third & $1.065^{* * *}$ \\
& $(0.097)$ \\
(\$20 Wage) X Slowest & $-0.611^{* * *}$ \\
& $(0.090)$ \\
(Hi Payoff) X Slowest & $-0.597^{* * *}$ \\
& $(0.078)$ \\
(\$20 Wage) X (Hi Payoff) X Slowest & $1.094^{* * *}$ \\
& $(0.13)$ \\
(\$20 Wage) X Middle & $0.217^{* * *}$ \\
& $(0.077)$ \\
$($ Hi Payoff) X Middle & $0.295^{* * *}$ \\
& $(0.087)$ \\
$(\$ 20$ Wage) X (Hi Payoff) X Middle & -0.0682 \\
& $(0.12)$ \\
$(\$ 20$ Wage) X Fastest & 0.0554 \\
& $(0.093)$ \\
(Hi Payoff) X Fastest & 0.0507 \\
& $(0.096)$ \\
$(\$ 20$ Wage) X (Hi Payoff) X Fastest & $-0.251^{* *}$ \\
& $(0.12)$ \\
Demographic Dummies & YES \\
Constant & $4.803^{* * *}$ \\
& $(0.25)$ \\
\hline Nobservations & 9300 \\
\hline & 186 \\
\hline \hline
\end{tabular}

Specification includes heteroskedastic and panel level AR-1 errors. Standard errors are reported in parentheses. Significance is denoted: ${ }^{*} p<0.10^{* *} p<0.05^{* * *} p<0.01$. Demographic dummies include dummy variables for gender, race, age, work experience, and student status. 
Table 7: Effects of Reciprocity with Speed Dummies

\begin{tabular}{|c|c|c|}
\hline Coefficients & & X Reciprocity \\
\hline Slowest Third & $\begin{array}{c}-0.432^{* * *} \\
(0.091)\end{array}$ & $\begin{array}{c}0.425^{* * *} \\
(0.15)\end{array}$ \\
\hline Fastest Third & $\begin{array}{c}-1.165^{* * *} \\
(0.12)\end{array}$ & $\begin{array}{r}-0.208 \\
(0.19)\end{array}$ \\
\hline (\$20 Wage) X Slowest & $\begin{array}{c}-0.377^{* * *} \\
(0.14)\end{array}$ & $\begin{array}{c}-0.390^{* *} \\
(0.19)\end{array}$ \\
\hline (Hi Payoff) X Slowest & $\begin{array}{c}-0.517^{* * *} \\
(0.097)\end{array}$ & $\begin{array}{c}-0.283 \\
(0.17)\end{array}$ \\
\hline (\$20 Wage) X (Hi Payoff) X Slowest & $\begin{array}{c}0.900^{* * *} \\
(0.18)\end{array}$ & $\begin{array}{c}0.440 \\
(0.27)\end{array}$ \\
\hline (\$20 Wage) X Middle & $\begin{array}{r}-0.129 \\
(0.12)\end{array}$ & $\begin{array}{c}0.629^{* * *} \\
(0.15)\end{array}$ \\
\hline (High Payoff) X Middle & $\begin{array}{c}0.281^{* * *} \\
(0.099)\end{array}$ & $\begin{array}{c}-0.569^{* * *} \\
(0.29)\end{array}$ \\
\hline (\$20 Wage) X (High Payoff) X Middle & $\begin{array}{l}0.155 \\
(0.16)\end{array}$ & $\begin{array}{c}0.295 \\
(0.32)\end{array}$ \\
\hline (\$20 Wage) X Fastest & $\begin{array}{c}-0.305^{* *} \\
(0.12)\end{array}$ & $\begin{array}{c}0.828^{* * *} \\
(0.18)\end{array}$ \\
\hline (High Payoff) X Fastest & $\begin{array}{c}-0.387^{* * *} \\
(0.13)\end{array}$ & $\begin{array}{c}0.978^{* * *} \\
(0.20)\end{array}$ \\
\hline (\$20 Wage) X (High Payoff) X Fastest & $\begin{array}{c}0.335^{* *} \\
(0.15)\end{array}$ & $\begin{array}{c}-1.656^{* * *} \\
(0.25)\end{array}$ \\
\hline Reciprocity Highest Third & $\begin{array}{c}-0.363^{* * *} \\
(0.11)\end{array}$ & \\
\hline Demographic Dummies & YES & \\
\hline Constant & $\begin{array}{c}5.150^{* * *} \\
(0.29)\end{array}$ & \\
\hline Observations & 9300 & \\
\hline Number of Subjects & 186 & \\
\hline
\end{tabular}

The first column reports main effects of treatment variables. The second column reports the coefficients for the interaction between the treatment variables and the reciprocity measure. The dummy for high reciprocity denotes subjects whose (Max \% Returned - Min \% Returned) is at the 66th percentile or higher. Specification includes heteroskedastic and panel level AR-1 errors. Standard errors are reported in parentheses. Significance is denoted: ${ }^{*} p<0.10^{* *} p<0.05^{* * *} p<0.01$. Demographic dummies include dummy variables for gender, race, age, work experience, and student status. 
Table 8: Reciprocity and Personality Characteristics

\begin{tabular}{lc}
\hline \hline Coefficients & $\mathbf{( 1 )}$ \\
\hline \hline Agreeableness & $0.0269^{*}$ \\
& $(0.015)$ \\
Extraversion & -0.0242 \\
& $(0.016)$ \\
Conscientiousness & -0.0110 \\
& $(0.015)$ \\
Emotional Stability & -0.0192 \\
& $(0.015)$ \\
Imagination & 0.0245 \\
& $(0.016)$ \\
Constant & $0.230^{* * *}$ \\
& $(0.014)$ \\
\hline Observations & 192 \\
\hline
\end{tabular}

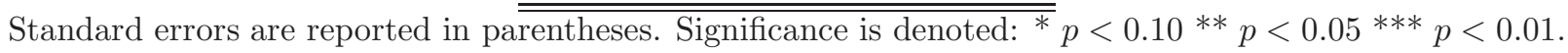


Table 9: Effect of Agreeableness with Speed Dummies

\begin{tabular}{|c|c|c|}
\hline Coefficients & & X Agreeable \\
\hline Slowest Third & $\begin{array}{c}-0.238^{* * *} \\
(0.085)\end{array}$ & $\begin{array}{c}-0.115 \\
(0.19)\end{array}$ \\
\hline Fastest Third & $\begin{array}{c}1.359^{* * *} \\
(0.12)\end{array}$ & $\begin{array}{c}-0.676^{* * *} \\
(0.20)\end{array}$ \\
\hline (\$20 Wage) X Slowest & $\begin{array}{c}-0.700^{* * *} \\
(0.095)\end{array}$ & $\begin{array}{c}1.027^{* * *} \\
(0.32)\end{array}$ \\
\hline (Hi Payoff) X Slowest & $\begin{array}{c}-0.313^{* * *} \\
(0.093)\end{array}$ & $\begin{array}{c}-0.521^{* * *} \\
(0.18)\end{array}$ \\
\hline (\$20 Wage) X (Hi Payoff) X Slowest & $\begin{array}{c}0.925^{* * *} \\
(0.14)\end{array}$ & $\begin{array}{r}-0.549 \\
(0.39)\end{array}$ \\
\hline (\$20 Wage) X Middle & $\begin{array}{c}0.313^{* * *} \\
(0.094)\end{array}$ & $\begin{array}{l}-0.285 \\
(0.18)\end{array}$ \\
\hline (High Payoff) X Middle & $\begin{array}{c}0.303^{* * *} \\
(0.097)\end{array}$ & $\begin{array}{c}-0.0842 \\
(0.26)\end{array}$ \\
\hline (\$20 Wage) X (High Payoff) X Middle & $\begin{array}{r}-0.156 \\
(0.14)\end{array}$ & $\begin{array}{r}0.250 \\
(0.30)\end{array}$ \\
\hline (\$20 Wage) X Fastest & $\begin{array}{c}-0.240^{* *} \\
(0.12)\end{array}$ & $\begin{array}{c}0.644^{* * *} \\
(0.19)\end{array}$ \\
\hline (High Payoff) X Fastest & $\begin{array}{c}-0.173 \\
(0.14)\end{array}$ & $\begin{array}{c}0.577^{* * *} \\
(0.20)\end{array}$ \\
\hline (\$20 Wage) X (High Payoff) X Fastest & $\begin{array}{l}-0.131 \\
(0.16)\end{array}$ & $\begin{array}{l}-0.177 \\
(0.24)\end{array}$ \\
\hline Agreeable Highest Quarter & $\begin{array}{c}0.00637 \\
(0.13)\end{array}$ & \\
\hline Demographic Dummies & YES & \\
\hline Constant & $\begin{array}{c}4.809^{* * *} \\
(0.26)\end{array}$ & \\
\hline Observations & 9300 & \\
\hline Number of Subjects & 186 & \\
\hline
\end{tabular}

The first column reports main effects of treatment variables. The second column reports the coefficients for the interaction between the treatment variables and the reciprocity measure. The dummy for high agreeableness denotes subjects whose agreeableness score is at the 75th percentile or higher. Specification includes heteroskedastic and panel level AR-1 errors. Standard errors are reported in parentheses. Significance is denoted: ${ }^{*} p<0.10^{* *} p<0.05^{* * *} p<0.01$. Demographic dummies include dummy variables for gender, race, age, work experience, and student status. 


\section{Experimental Instructions}

Screen 1

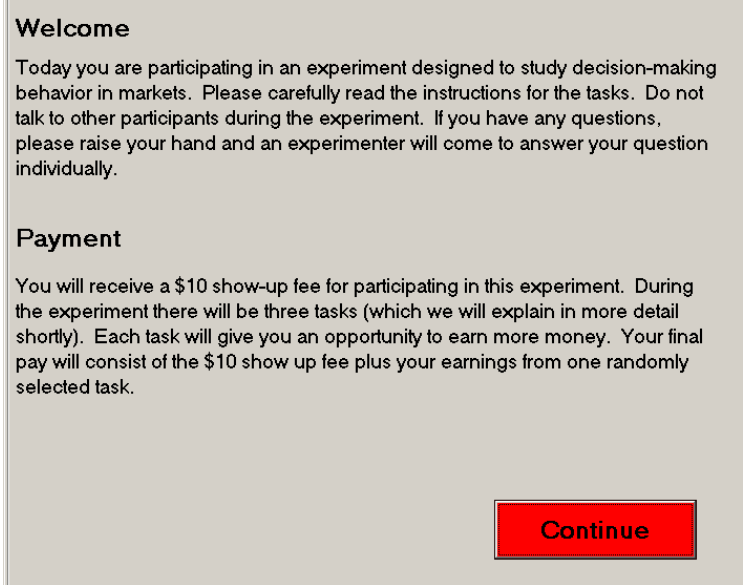

Screen 2

Coding Task - General Instructions

In this task, you will be randomly chosen to be either a "Manager" or a

"Worker". Each Worker will be randomly matched with one Manager. The

Manager will have an opportunity to hire the Worker to perform a task, the

"Coding Task", for 25 minutes. 
Screen 3

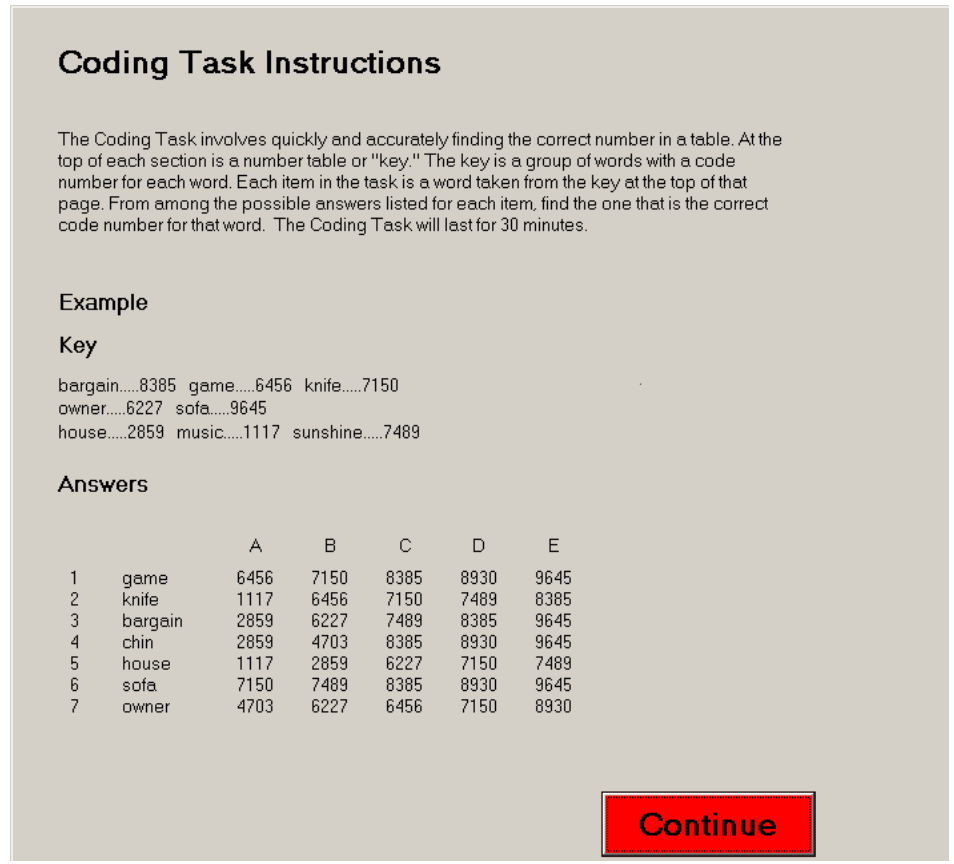

Screen $4 \mathrm{a}$

\section{Payments}

If this task is randomly selected for payment, you will get the following (in addition to your show-up fee):

If you are a Worker, you get $\$ 0$ if you are not hired, and you get your wage if you are hired.

If you are a Manager and do not hire a Worker, you receive $\$ 0$. If you do hire a Worker, you receive $\$ 40$ plus $\$ 0.04$ for every answer the Worker gets correct minus $\$ 0.01$ for every answer the worker gets incorrect minus the wage payment to the Worker.

For example, if a Manager hires a Worker for a $\$ 10$ wage and the Worker gets 200 correct answers and 3 incorrect answers, the Workers payoff would be $\$ 10$ and the Managers Payoff would be:

$\$ 40+\$ 0.04 * 200-\$ 0.01 * 3-\$ 10=\$ 37.97$

\section{Continue}


Screen $4 b$

\section{Payments}

If this task is randomly selected for payment, you will get the following (in addition to your show-up fee):

If you are a Worker, you get $\$ 0$ if you are not hired, and you get your wage if you are hired.

If you are a Manager and do not hire a Worker, you receive $\$ 0$. If you do hire a Worker, you receive $\$ 10$ plus $\$ 0.20$ for every answer the Worker gets correct minus $\$ 0.05$ for every answer the worker gets incorrect minus the wage payment to the Worker.

For example, if a Manager hires a Worker for a $\$ 10$ wage and the Worker gets 200 correct answers and 3 incorrect answers, the Workers payoft would be $\$ 10$ and the Managers Payoff would be:

$\$ 10+\$ 0.20 * 200-\$ 0.05 * 3-\$ 10=\$ 39.85$

\section{Screen $5 \mathrm{a}$}

You are a Worker

Please wait while the Managers make their decisions.

\section{Continue}

\section{Continue}

Screen $5 b$

\section{You are a Manager}

Do you want to hire a Worker at a wage of $\$ 10$ ?

- Do not hire a worker

c Hire a Worker at a wage of $\$ 10$ 
Screen $5 c$

\section{You are a Manager}

Instead of hiring a Worker at a wage of $\$ 10$, you can hire a Worker at a wage of $\$ 20$. If you choose the wage of $\$ 10$, the Worker will not know that you had the option to offer $\$ 20$.

- Do not hire a Worker

c Hire a Worker at a wage of $\$ 10$

c Hire a Worker at a wage of $\$ 20$

\section{Continue}

Screen $6 a$

A Manager has hired you to perform the Coding Task at a wage of $\$ 10$.

When You are Ready to Proceed Press Begin

\section{Begin}

Screen $6 b$

A Manager has hired you and has decided to raise your wage for the Coding Task to $\$ 20$ from the announced $\$ 10$

When You are Ready to Proceed Press Begin 


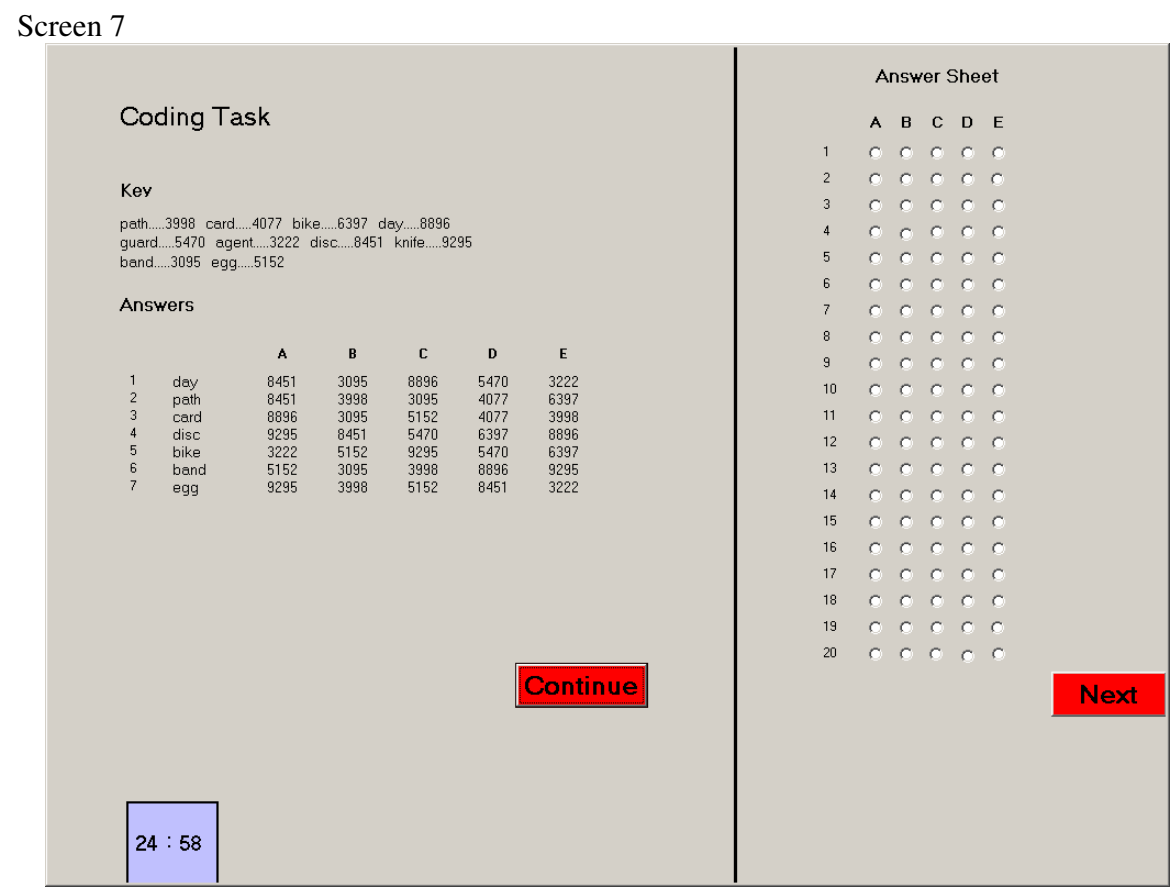

Screen 8

\section{Second Task}

You will now perform a 5 minute Coding Task. There are no Managers and Workers for this task. You will be paid $\$ 0.30$ for every correct answer, minus $\$ 0.08$ for every incorrect answer, if this task is selected for payment. Press Begin to start the task.

\section{Begin}




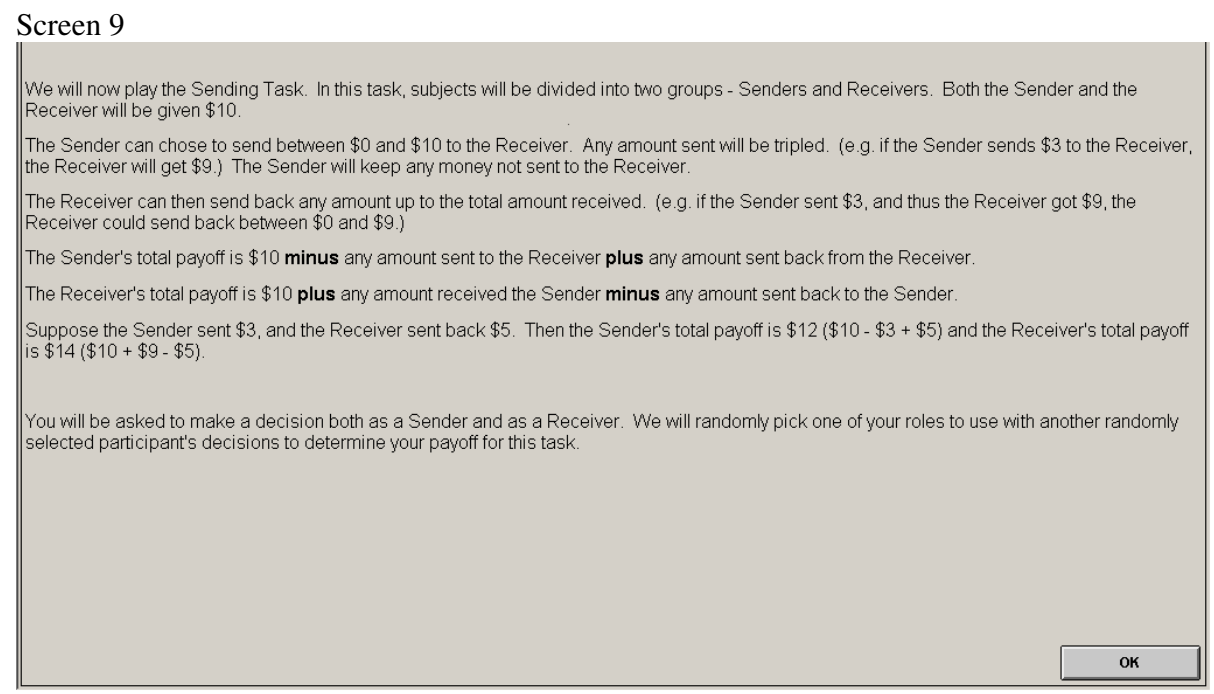

Screen 10

Please select how much you would like to send to the Recipient if you are the Sender.

$C$ Send $\$ 0$

$C$ Send $\$ 1$

$C$ Send $\$ 2$

$C$ Send $\$ 3$

$C$ Send $\$ 4$

$C$ Send $\$ 5$

$C$ Send $\$ 6$

$C$ Send $\$ 7$

$C$ Send $\$ 8$

$C$ Send $\$ 9$

$C$ Send $\$ 10$ 


\section{Screen 11}

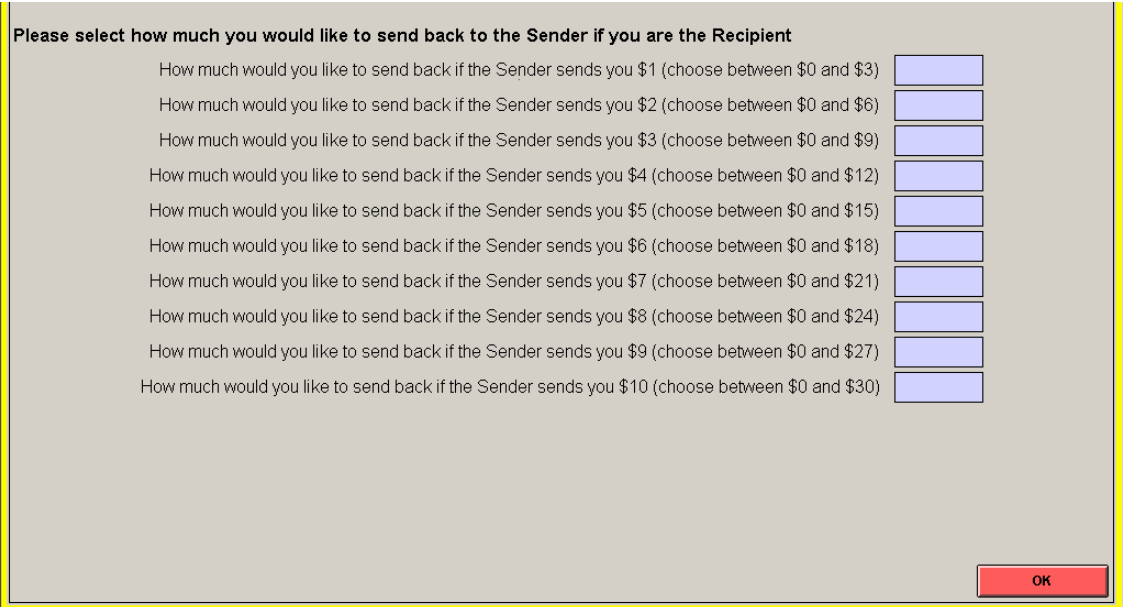

Screen $12 \mathrm{a}$ and $\mathrm{b}$

\begin{tabular}{|c|c|c|}
\hline Age & & \\
\hline Sex & C Male & \\
\hline Race & $\begin{array}{l}C \text { Asian } \\
C \text { Black } \\
C \text { Caucasian } \\
C \text { Hispanic } \\
C \text { Other }\end{array}$ & \\
\hline \multicolumn{3}{|l|}{ If other, please specify } \\
\hline Are you currently a & $\begin{array}{l}\text { C Undergraduate Student, not working } \\
\text { C Undergraduate Student, working part time } \\
\text { C Undergraduate Student, working full time } \\
\text { C Graduate Student, not working } \\
\text { C Graduate Student, working part time } \\
\text { C Graduate Student, working full time } \\
\text { C Not a Student, not working } \\
\text { C Student, working part time } \\
\text { C Student, working fult time } \\
\text { S None of the Above }\end{array}$ & \\
\hline How many years work experience do you have? & & GK \\
\hline If you are a student, what university do you attend? & $\begin{array}{l}C \text { Boston College } \\
\text { B Boston University } \\
C \text { Havard } \\
\text { M MT } \\
C \text { Northeastern } \\
C \text { Tufts } \\
C \text { U Mass } \\
C \text { Other }\end{array}$ & \\
\hline \multicolumn{3}{|l|}{ If other, please specify } \\
\hline $\begin{array}{l}\text { If you are a student, what is your } \\
\text { major/concentration? }\end{array}$ & 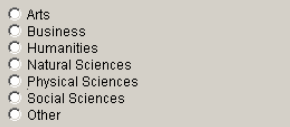 & \\
\hline \multicolumn{3}{|l|}{ If other, please specify } \\
\hline What is your highest completed degree? & $\begin{array}{l}C \text { High SchooliGED } \\
C \text { Associates Degree } \\
C \text { Bachelors Degree } \\
C \text { Masters Degree or Higher } \\
C \text { None of the Above }\end{array}$ & \\
\hline \multirow[t]{2}{*}{ Have you participated in a CLER experiment before? } & $\begin{array}{c}\text { CNo } \\
\text { Yes }\end{array}$ & \\
\hline & & OK \\
\hline
\end{tabular}


Screen 13a-c

\begin{tabular}{|c|c|c|c|c|c|}
\hline \multicolumn{6}{|c|}{ 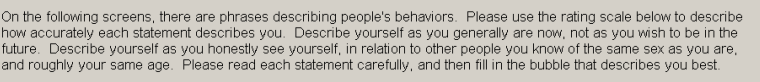 } \\
\hline & Voy hasecertate & 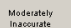 & 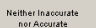 & 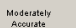 & VoryAcesita \\
\hline Am the life of the party & 0 & $c$ & c & $c$ & c \\
\hline Feal Iitle concern for others & c & c & c & c & c \\
\hline Am alweys prepared & c & c & c & c & $c$ \\
\hline Get stressed out easily & c & c & c & c & $c$ \\
\hline Have a nch rocabulary & c. & c & c & c & c \\
\hline Don't talk a lot & c & c & c & c & c \\
\hline Am interested in people & c & c & c & c & c \\
\hline Leave my belongings around & o & c & $c$ & c & $c$ \\
\hline Am relexed most of the time & $c$ & c & c & c & c \\
\hline Have difificully understanding abstract ideas & c & $c$ & 0 & c & c \\
\hline Fe日l comfortable around people & o & c & c & c & c \\
\hline Insult people & 0 & c & 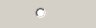 & c & c \\
\hline Pay attention to details & c & $c$ & $c$ & $c$ & $c$ \\
\hline Worry about things & c & $c$ & 0 & 0 & c \\
\hline Have a vivd imagination & c & c & c & c & $c$ \\
\hline \multirow[t]{3}{*}{ Change my mind a lot } & c & $\mathrm{c}$ & c & c & $\mathrm{c}$ \\
\hline & & & & \multicolumn{2}{|c|}{ OK } \\
\hline & 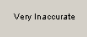 & 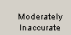 & 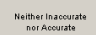 & 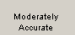 & Vey A Aceurate \\
\hline Am quick to understanding things & c & $c$ & $c$ & 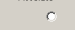 & c \\
\hline Don't like to draw attention to myseff & $c$ & $c$ & $c$ & c & $c$ \\
\hline Take time out for others & c & c & c & c & c \\
\hline Shirk my duties & c & c & $\mathrm{c}$ & c & c \\
\hline Have trequent mood swings & o & $c$ & c & c & c \\
\hline Use difficut words & c & c & c & c & c \\
\hline Don't mind being the center of attention & c & c & $\mathrm{c}$ & c & c \\
\hline Feel others' emotions & c. & c & c & c & c \\
\hline Followa schedule & $c$ & $c$ & c & $\mathrm{c}$ & c \\
\hline Get iritated easily & $\mathrm{c}$ & c & c & c & c \\
\hline Spend time reflecting on things & c & c & c & $\mathrm{c}$ & $c$ \\
\hline Am quiet around strangers & c & c & c & c & 0 \\
\hline Make people feel at ease & $\mathrm{c}$ & r & c & c & c \\
\hline Am exacting in my work & c & c & c & 0 & c \\
\hline Often feel blue & c & c & c & c & c \\
\hline Am full of ideas & $c$ & 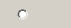 & c & $c$ & 0 \\
\hline \multirow[t]{3}{*}{ Keep in the background } & c & c & c & c & c \\
\hline & & & & \multicolumn{2}{|c|}{ oK } \\
\hline & vey Iraccusale & 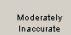 & 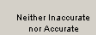 & 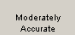 & Venf Acerurate \\
\hline Sumpathize with others' feelings & c & $\circ$ & $\circ$ & $c$ & c \\
\hline Make a mess of things & c & c & c & c & c \\
\hline Seldom feel blue & c & c & c & c & c \\
\hline Am not interested in abstract ideas & c & $c$ & c & $c$ & c \\
\hline Start conversations & $\mathrm{c}$ & c & c & c & c \\
\hline Am not interested in other people's problems & c & c & c & c & c \\
\hline Get chores done right away & c & c & c & c & c \\
\hline Am easily cisturbed & c. & c & c & c & c \\
\hline Have excellent ideas & c & c & c & $c$ & c \\
\hline Have little to say & c & c & c & c & c \\
\hline Have a sot heart & c & $c$ & c & c & c \\
\hline Otten forget to put things back in their proper place & c & c & c & c & c \\
\hline Get upset easily & $\mathrm{c}$ & c & $c$ & c & c \\
\hline Do not heve a good imagination & c & $c$ & c & c & c \\
\hline Talk to a lot of differert people at parties & $c$ & $c$ & c & $c$ & c \\
\hline Am not really interested in others & $c$ & $r$ & $c$ & $c$ & 0 \\
\hline \multirow[t]{2}{*}{ Like order } & $c$ & $c$ & c & c & c \\
\hline & & & & & ok \\
\hline
\end{tabular}




\section{CESifo Working Paper Series}

for full list see www.cesifo-group.org/wp

(address: Poschingerstr. 5, 81679 Munich, Germany, office@cesifo.de)

2881 Marko Koethenbuerger and Michael Stimmelmayr, Corporate Taxation and Corporate Governance, December 2009

2882 Gebhard Kirchgässner, The Lost Popularity Function: Are Unemployment and Inflation no longer Relevant for the Behaviour of Germany Voters?, December 2009

2883 Marianna Belloc and Ugo Pagano, Politics-Business Interaction Paths, December 2009

2884 Wolfgang Buchholz, Richard Cornes and Dirk Rübbelke, Existence and Warr Neutrality for Matching Equilibria in a Public Good Economy: An Aggregative Game Approach, December 2009

2885 Charles A.E. Goodhart, Carolina Osorio and Dimitrios P. Tsomocos, Analysis of Monetary Policy and Financial Stability: A New Paradigm, December 2009

2886 Thomas Aronsson and Erkki Koskela, Outsourcing, Public Input Provision and Policy Cooperation, December 2009

2887 Andreas Ortmann, "The Way in which an Experiment is Conducted is Unbelievably Important": On the Experimentation Practices of Economists and Psychologists, December 2009

2888 Andreas Irmen, Population Aging and the Direction of Technical Change, December 2009

2889 Wolf-Heimo Grieben and Fuat Şener, Labor Unions, Globalization, and Mercantilism, December 2009

2890 Conny Wunsch, Optimal Use of Labor Market Policies: The Role of Job Search Assistance, December 2009

2891 Claudia Buch, Cathérine Tahmee Koch and Michael Kötter, Margins of International Banking: Is there a Productivity Pecking Order in Banking, too?, December 2009

2892 Shafik Hebous and Alfons J. Weichenrieder, Debt Financing and Sharp Currency Depreciations: Wholly vs. Partially Owned Multinational Affiliates, December 2009

2893 Johannes Binswanger and Daniel Schunk, What is an Adequate Standard of Living during Retirement?, December 2009

2894 Armin Falk and James J. Heckman, Lab Experiments are a Major Source of Knowledge in the Social Sciences, December 2009

2895 Hartmut Egger and Daniel Etzel, The Impact of Trade on Employment, Welfare, and Income Distribution in Unionized General Oligopolistic Equilibrium, December 2009 
2896 Julian Rauchdobler, Rupert Sausgruber and Jean-Robert Tyran, Voting on Thresholds for Public Goods: Experimental Evidence, December 2009

2897 Michael McBride and Stergios Skaperdas, Conflict, Settlement, and the Shadow of the Future, December 2009

2898 Ben J. Heijdra and Laurie S. M. Reijnders, Economic Growth and Longevity Risk with Adverse Selection, December 2009

2899 Johannes Becker, Taxation of Foreign Profits with Heterogeneous Multinational Firms, December 2009

2900 Douglas Gale and Piero Gottardi, Illiquidity and Under-Valuation of Firms, December 2009

2901 Donatella Gatti, Christophe Rault and Anne-Gaël Vaubourg, Unemployment and Finance: How do Financial and Labour Market Factors Interact?, December 2009

2902 Arno Riedl, Behavioral and Experimental Economics Can Inform Public Policy: Some Thoughts, December 2009

2903 Wilhelm K. Kohler and Marcel Smolka, Global Sourcing Decisions and Firm Productivity: Evidence from Spain, December 2009

2904 Marcel Gérard and Fernando M. M. Ruiz, Corporate Taxation and the Impact of Governance, Political and Economic Factors, December 2009

2905 Mikael Priks, The Effect of Surveillance Cameras on Crime: Evidence from the Stockholm Subway, December 2009

2906 Xavier Vives, Asset Auctions, Information, and Liquidity, January 2010

2907 Edwin van der Werf, Unilateral Climate Policy, Asymmetric Backstop Adoption, and Carbon Leakage in a Two-Region Hotelling Model, January 2010

2908 Margarita Katsimi and Vassilis Sarantides, Do Elections Affect the Composition of Fiscal Policy?, January 2010

2909 Rolf Golombek, Mads Greaker and Michael Hoel, Climate Policy without Commitment, January 2010

2910 Sascha O. Becker and Ludger Woessmann, The Effect of Protestantism on Education before the Industrialization: Evidence from 1816 Prussia, January 2010

2911 Michael Berlemann, Marco Oestmann and Marcel Thum, Demographic Change and Bank Profitability. Empirical Evidence from German Savings Banks, January 2010

2912 Øystein Foros, Hans Jarle Kind and Greg Shaffer, Mergers and Partial Ownership, January 2010 
2913 Sean Holly, M. Hashem Pesaran and Takashi Yamagata, Spatial and Temporal Diffusion of House Prices in the UK, January 2010

2914 Christian Keuschnigg and Evelyn Ribi, Profit Taxation and Finance Constraints, January 2010

2915 Hendrik Vrijburg and Ruud A. de Mooij, Enhanced Cooperation in an Asymmetric Model of Tax Competition, January 2010

2916 Volker Meier and Martin Werding, Ageing and the Welfare State: Securing Sustainability, January 2010

2917 Thushyanthan Baskaran and Zohal Hessami, Globalization, Redistribution, and the Composition of Public Education Expenditures, January 2010

2918 Angel de la Fuente, Testing, not Modelling, the Impact of Cohesion Support: A Theoretical Framework and some Preliminary Results for the Spanish Regions, January 2010

2919 Bruno S. Frey and Paolo Pamini, World Heritage: Where Are We? An Empirical Analysis, January 2010

2920 Susanne Ek and Bertil Holmlund, Family Job Search, Wage Bargaining, and Optimal Unemployment Insurance, January 2010

2921 Mariagiovanna Baccara, Allan Collard-Wexler, Leonardo Felli and Leeat Yariv, Gender and Racial Biases: Evidence from Child Adoption, January 2010

2922 Kurt R. Brekke, Roberto Cellini, Luigi Siciliani and Odd Rune Straume, Competition and Quality in Regulated Markets with Sluggish Demand, January 2010

2923 Stefan Bauernschuster, Oliver Falck and Niels Große, Can Competition Spoil Reciprocity? - A Laboratory Experiment, January 2010

2924 Jerome L. Stein, A Critique of the Literature on the US Financial Debt Crisis, January 2010

2925 Erkki Koskela and Jan König, Profit Sharing, Wage Formation and Flexible Outsourcing under Labor Market Imperfection, January 2010

2926 Gabriella Legrenzi and Costas Milas, Spend-and-Tax Adjustments and the Sustainability of the Government's Intertemporal Budget Constraint, January 2010

2927 Piero Gottardi, Jean Marc Tallon and Paolo Ghirardato, Flexible Contracts, January 2010

2928 Gebhard Kirchgässner and Jürgen Wolters, The Role of Monetary Aggregates in the Policy Analysis of the Swiss National Bank, January 2010 
2929 J. Trent Alexander, Michael Davern and Betsey Stevenson, Inaccurate Age and Sex Data in the Census PUMS Files: Evidence and Implications, January 2010

2930 Stefan Krasa and Mattias K. Polborn, Competition between Specialized Candidates, January 2010

2931 Yin-Wong Cheung and Xingwang Qian, Capital Flight: China's Experience, January 2010

2932 Thomas Hemmelgarn and Gaetan Nicodeme, The 2008 Financial Crisis and Taxation Policy, January 2010

2933 Marco Faravelli, Oliver Kirchkamp and Helmut Rainer, Social Welfare versus Inequality Concerns in an Incomplete Contract Experiment, January 2010

2934 Mohamed El Hedi Arouri and Christophe Rault, Oil Prices and Stock Markets: What Drives what in the Gulf Corporation Council Countries?, January 2010

2935 Wolfgang Lechthaler, Christian Merkl and Dennis J. Snower, Monetary Persistence and the Labor Market: A New Perspective, January 2010

2936 Klaus Abberger and Wolfgang Nierhaus, Markov-Switching and the Ifo Business Climate: The Ifo Business Cycle Traffic Lights, January 2010

2937 Mark Armstrong and Steffen Huck, Behavioral Economics as Applied to Firms: A Primer, February 2010

2938 Guglielmo Maria Caporale and Alessandro Girardi, Price Formation on the EuroMTS Platform, February 2010

2939 Hans Gersbach, Democratic Provision of Divisible Public Goods, February 2010

2940 Adam Isen and Betsey Stevenson, Women's Education and Family Behavior: Trends in Marriage, Divorce and Fertility, February 2010

2941 Peter Debaere, Holger Görg and Horst Raff, Greasing the Wheels of International Commerce: How Services Facilitate Firms' International Sourcing, February 2010

2942 Emanuele Forlani, Competition in the Service Sector and the Performances of Manufacturing Firms: Does Liberalization Matter?, February 2010

2943 James M. Malcomson, Do Managers with Limited Liability Take More Risky Decisions? An Information Acquisition Model, February 2010

2944 Florian Englmaier and Steve Leider, Gift Exchange in the Lab - It is not (only) how much you give ..., February 2010 